\title{
WestVirginiaUniversity
}

THE RESEARCH REPOSITORY @ WVU

Graduate Theses, Dissertations, and Problem Reports

2012

\section{Insertion loss of a simple plywood noise enclosure}

Justin Lamper

West Virginia University

Follow this and additional works at: https://researchrepository.wvu.edu/etd

\section{Recommended Citation}

Lamper, Justin, "Insertion loss of a simple plywood noise enclosure" (2012). Graduate Theses,

Dissertations, and Problem Reports. 3332.

https://researchrepository.wvu.edu/etd/3332

This Thesis is protected by copyright and/or related rights. It has been brought to you by the The Research Repository @ WVU with permission from the rights-holder(s). You are free to use this Thesis in any way that is permitted by the copyright and related rights legislation that applies to your use. For other uses you must obtain permission from the rights-holder(s) directly, unless additional rights are indicated by a Creative Commons license in the record and/ or on the work itself. This Thesis has been accepted for inclusion in WVU Graduate Theses, Dissertations, and Problem Reports collection by an authorized administrator of The Research Repository @ WVU. For more information, please contact researchrepository@mail.wvu.edu. 
INSERTION LOSS OF A SIMPLE PLYWOOD NOISE ENCLOSURE

By

Justin Lamper

Thesis Submitted to the College of Engineering and Mineral Resources At West Virginia University In partial fulfillment of the requirements

For the degree of

Masters of Science

In

Industrial Hygiene

Approved by

Steve Guffey, PhD, Committee Chair

Michael Klishis PhD

Mohammed Abbas Virji ScD

Department of Industrial and Management Systems Engineering

Morgantown, West Virginia

2012

Keywords: Insertion Loss, Transmission Loss, Sound Absorption 


\section{ABSTRACT}

Noise enclosures are used to reduce noise exposures to the employee. Some problems with commercial noise enclosures is they tend to be expensive and often provide much more insertion loss (IL) than is truly needed. The two studies described here tested the effectiveness of a simple plywood noise enclosure with a size of $75 \mathrm{~cm} \times 75 \mathrm{~cm} \times 75 \mathrm{~cm}$. To determine the IL of the enclosure an OROS OR 38 noise analyzer was used in conjunction with eight PCB piezotronic microphones located at four and eight feet from the source perpendicular to each vertical side of the enclosure.

Study One tested the effects of insulation coverage (Insulation), measurement distance from sound source (Distance), and direction in the horizontal plane (Microphone Location) on the IL of the enclosure when there were no holes in the enclosure. The results of Study One showed that the bare enclosure ( $0 \%$ insulation) provided a $6.9 \mathrm{dBA}$ average IL. When the inner surfaces of the enclosure were covered with $50 \%$ and $83 \%$ of Insulation coverage, the IL values were 10.2 and $11.0 \mathrm{dBA}$, respectively.

Study Two tested the conditions listed in Study One as well as the effects of adding Hole Diameters of 2" and 4" at different times. It also included rotating the enclosure so the Hole Direction was either facing $0^{\circ}$ or $180^{\circ}$ from the original orientation. The results of Study Two showed that the average IL of the enclosure was reduced by $0.8 \mathrm{dBA}$ when there was a 2 " hole in the enclosure and by $1.7 \mathrm{dBA}$ when there was a 4 " hole in the enclosure.

The most important conclusion reached from the two studies was a simple noise enclosure can be constructed of plywood and it will be effective to some degree even if there all holes in it. The minimum IL this enclosure produced was $5.3 \mathrm{dBA}$ when there was a 4 " hole in one side. In many cases this would be sufficient enough to reduce a company underneath regulatory standards. 


\section{Dedication}

To my parents David and Alice for all their support through all my academic endeavors 


\section{ACKNOWLEDGMENTS}

This research was supported by grant funding (IR010005) the National Institute for

Occupational Safety and Health. I would like to thank Dr. Steve Guffey for all his time and patience and guidance throughout this thesis. I would also like to thank Steve Kasberger for the time he spent setting up and collecting data. Finally, I would like to thank Jamal Dajani, John Woods and the entire OROS Corporation for providing us the latest version of NVGATE Software and for their excellent technical support. 


\section{TABLE OF CONTENTS}

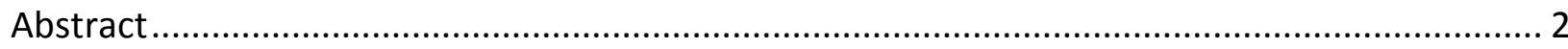

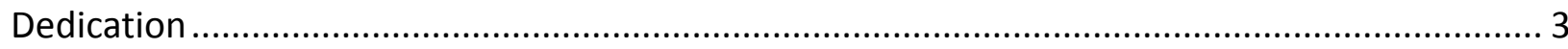

Acknowledgments................................................................................................................. 4

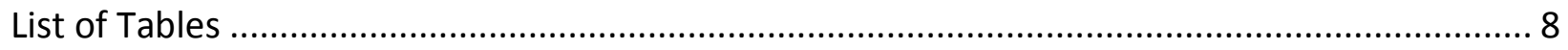

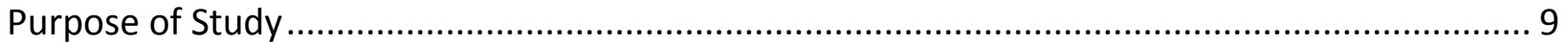

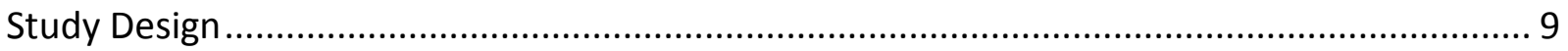

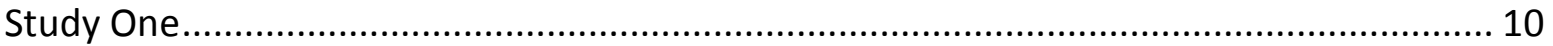

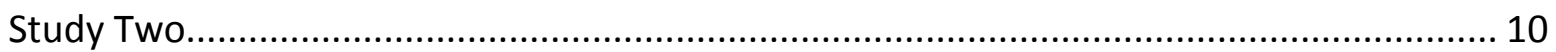

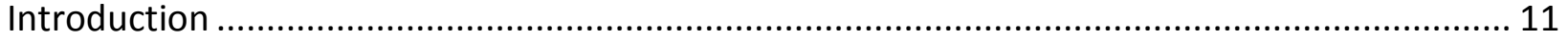

Noise Problems in the Workplace .................................................................................... 11

Approaches to Limiting Employees Exposure to Noise............................................................ 12

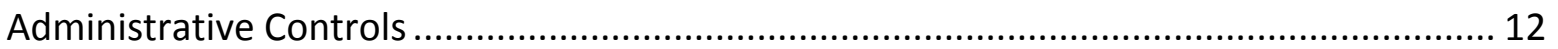

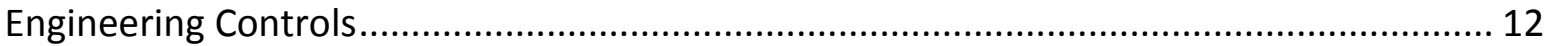

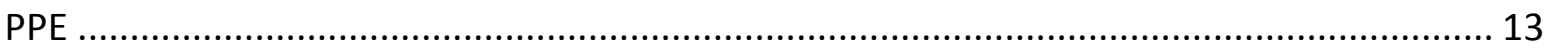

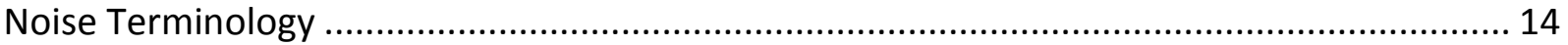

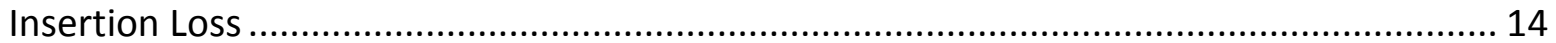

Transmission Loss and Noise Reduction ................................. Error! Bookmark not defined.

Absorption and Attenuation ................................................... Error! Bookmark not defined.

Predicting Sound Absorption ....................................................................................... 15

Predicting Transmission Loss ................................................ Error! Bookmark not defined.

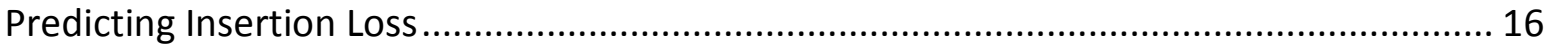

Reverberant Build Up.......................................................... Error! Bookmark not defined.

Near and Far Field ...................................................................................................... 17

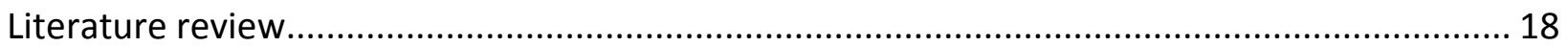

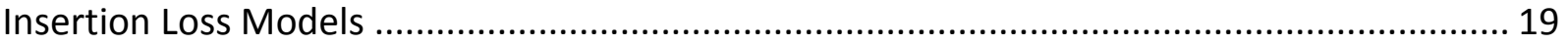

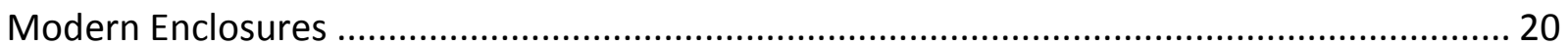

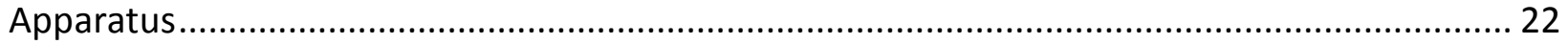

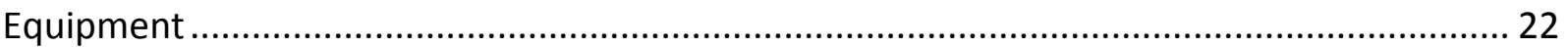




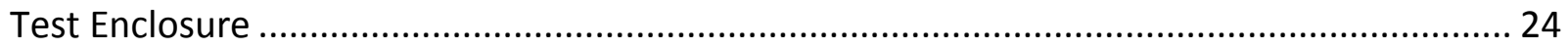

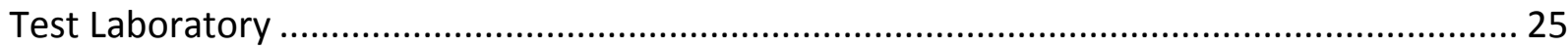

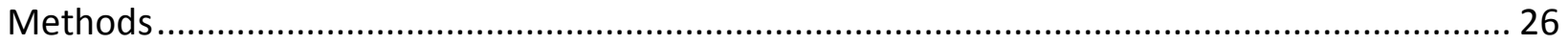

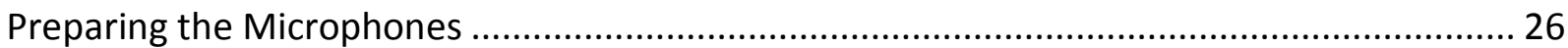

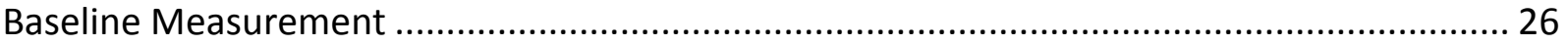

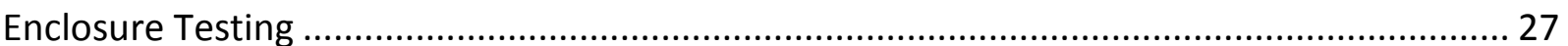

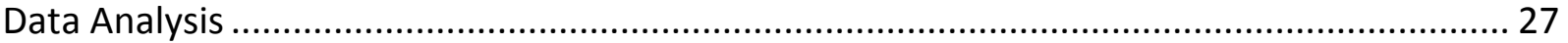

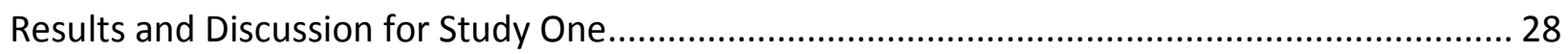

Statistical Analysis ................................................................ Error! Bookmark not defined.

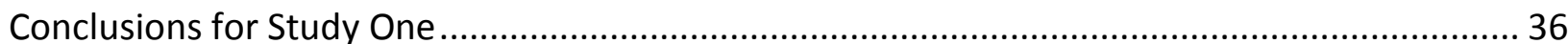

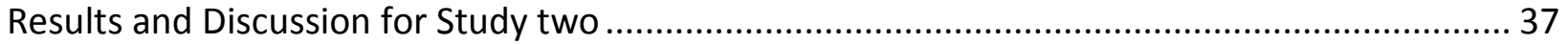

Statistical Analysis ..................................................................... Error! Bookmark not defined.

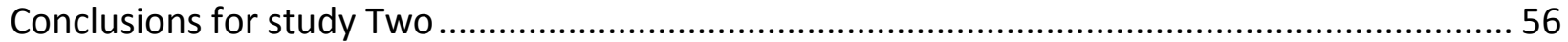

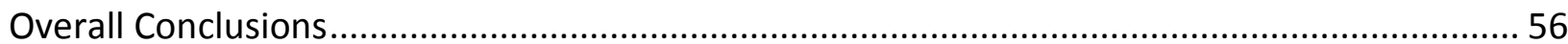

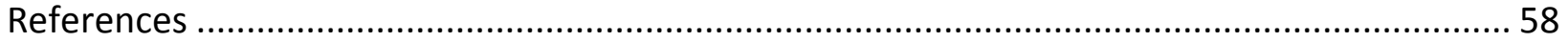

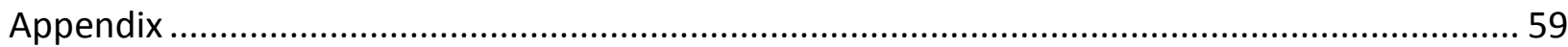

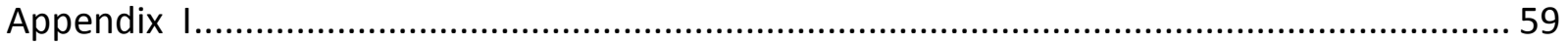




\section{LIST OF FIGURES}

Figure 1. Cross-section of a Typical Noise Enclosure Wall.................................................... 19

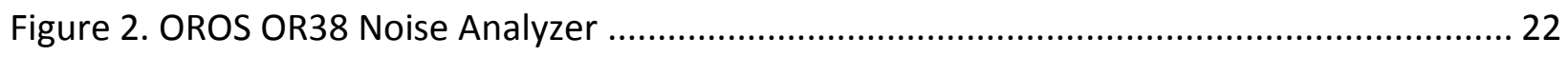

Figure 3. Speaker Location on Metal Pedestal ........................................................................ 23

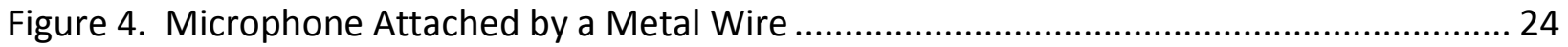

Figure 5. Top view schematic of test set up Error! Bookmark not defined.

Figure 6. Location of the Enclosure within the Room ....................................................... 26

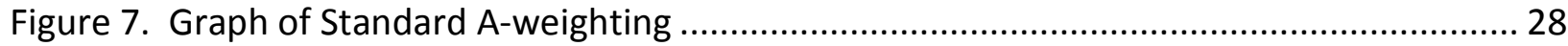

Figure 8. SPL $\mathrm{L}_{\mathrm{i}}$ values at a distance of 4 and 8 feet from the sound source. ..............................29

Figure 9. Average insertion loss across all levels of insulation ............................................... 32

Figure 10. Insertion Loss of enclosure with all levels of insulation Error! Bookmark not defined.

Figure 11. Average Insertion Loss of noise enclosure with 2" hole...................................... 38

Figure 12. Effect of insulation on IL of enclosure with 2" hole and........................................ 39

Figure 13. Effect of hole direction on IL of enclosure with 2 " hole and all levels of insulation

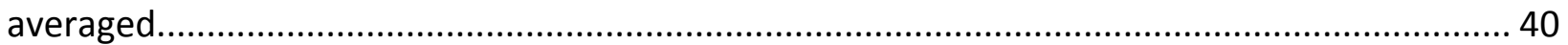

Figure 14. Average IL of enclosure with 4 " hole ................................................................ 42

Figure 15. Effect of insulation on IL of enclosure with a 4 " hole ............................................ 43

Figure 16. Effect of hole direction on IL of enclosure with 4" hole averaged across .................. 44

Figure 17. Effects of all sizes of hole on IL when there was $0 \%$ insulation ............................. 46

Figure 18. Effects of all sizes of hole on IL when there was $0 \%$ insulation at the speaker facing $180^{\circ}$

Figure 19. Insertion Loss of enclosure with $100 \%$ insulation and hole facing $0^{\circ}$. Error! Bookmark not defined.

Figure 20. Insertion Loss of enclosure with $100 \%$ insulation and hole facing $180^{\circ} \ldots \ldots \ldots \ldots \ldots . . . . . . . .49$

Figure 21. Effect of Hole Direction on Insertion Loss across all............................................ 51

Figure 22. Effect of Hole Direction on Insertion Loss across ............................................. 52 


\section{LIST OF TABLES}

Table 1. Standard Transmission Coefficients of Various Materials ......................................... 14

Table 2 Amount of Sound Reduction Based upon Absorptive Material Inserted into Noise

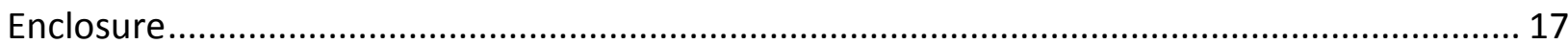

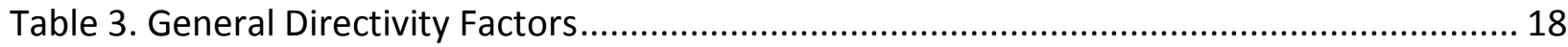

Table 4. Plywood Noise Enclosure Calculations..................................................................... 25

Table 5. Test Conditions of the Plywood Noise Enclosure.................................................... 27

Table 6. $\mathrm{SPL}_{\mathrm{i}}$ Values of No Enclosure and Enclosure in all Directions...................................... 29

Table 7. Insertion Loss of Noise Enclosure with Varying amounts of Insulation....................... 30

Table 8. Comparison of predicted and actual IL values based upon the................................. 33

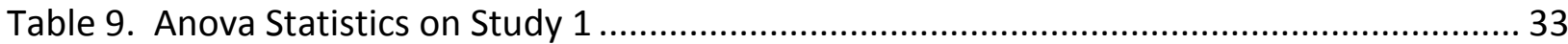

Table 10. Scheffe Post Hoc on Amount of Insulation ......................................................... 34

Table 11. Scheffe Post Hoc Test on Location ........................................................................ 34

Table 12. Scheffe Post Hoc on the Interactive effect of Mic Location and Distance ................... 35

Table 13. Insertion Loss of noise enclosure with 2 " hole ........................................................ 37

Table 14. Insertion Loss of Noise Enclosure with 4" hole.................................................... 41

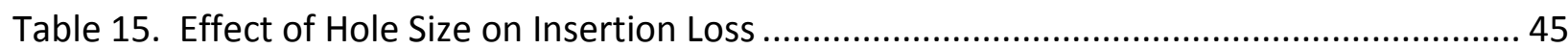

Table 16. Effect of Hole Direction on Insertion Loss............................................................. 50

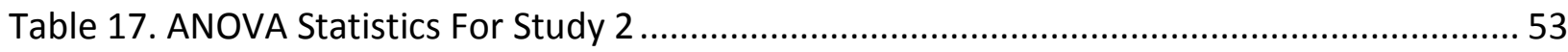

Table 18. Scheffe Post Hoc of the Interaction Between Hole Direction and Mic Location ......... 54

Table 19. Scheffe Post Hoc on the Interactive Effect of Distance and Hole Diameter............... 55 


\section{PURPOSE OF STUdY}

Noise enclosures are used in industry to limit employee's exposure to noise. The major problem with modern enclosures is they are very expensive, perhaps because they are overdesigned to provide much more insertion loss than is needed. These studies focused on designing and testing a small enclosure constructed of plywood that could be potentially used to enclosure a small sound source in an industrial setting. The way the effectiveness of the enclosure was measured was the Insertion Loss (IL) that the enclosure produced.

\section{Study Design}

This investigation was divided into two studies that each had a factorial design. Study One determined the effect of adding insulation to the enclosure when there were no holes present. Study Two determined the effect of different Hole Diameters and the direction of the speaker relative to the hole. The reason for adding holes to the enclosure was to simulate an enclosure that would be used in industry because they are often designed completely without holes due to ventilation and maintenance doors. The dependent variable for each of the studies was IL. Both studies shared the independent variables of Microphone Location $\left(0^{\circ}, 90^{\circ}, 180^{\circ}\right.$ and $270^{\circ}$ ), Microphone Distance (Distance) from the source ( 4 and 8 feet) and the fraction of the enclosure covered with insulation (Insulation). Figure 1 shows the test set up and all of the microphone locations. The speaker always remained facing the direction deemed " 0 " even during tests where the enclosure was rotated $180^{\circ}$. The microphones remained at the same locations for all tests as well. 


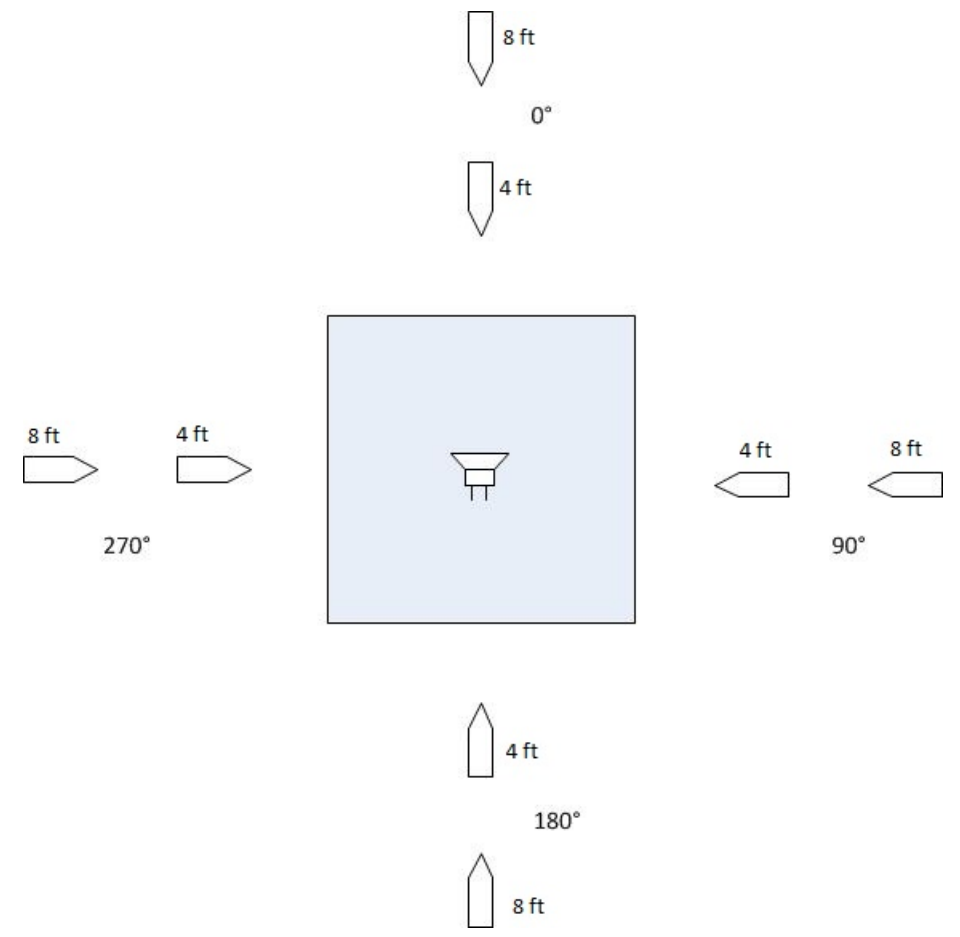

Figure 1. Top View Schematic of Test Set up

\section{Study One}

The variables analyzed in Study One are as follows:

Dependent Variable: Insertion Loss (IL)

Independent Variables:

1. Microphone location $\left(0^{\circ}, 90^{\circ}, 180^{\circ}\right.$ and $\left.270^{\circ}\right)$

2. Distance: 4 and 8 Feet. Measured from the center of the noise source to the microphone

3. Amount of Acoustical Insulation: $0 \%, 50 \%, 100 \%$

\section{Study Two}

The variables analyzed in Study two are as follows:

Dependent Variable: Insertion Loss (IL)

Independent Variables:

1. Microphone location $\left(0^{\circ}, 90^{\circ}, 180^{\circ}\right.$ and $\left.270^{\circ}\right)$ 
2. Distance: 4 and 8 Feet. Measured at the center on each side of the sound source

3. Amount of Acoustical Insulation: $0 \%$, and $100 \%$

4. Size of the opening: $0 \mathrm{~cm}^{2}, 20.27 \mathrm{~cm}^{2}$ (2" diameter hole), $81.07 \mathrm{~cm}^{2}$ (4" diameter hole)

5. Direction of Hole: $0^{\circ}$ and $180^{\circ}$

The aims of the studies were to:

1. Determine how IL changed with each independent variable

2. Compare observed and predicted IL values

The following hypotheses concerning the insertion loss (IL) of the enclosure under various conditions were tested:

$\mathrm{H}_{0}: \mathrm{IL}_{\text {With Enclosure }}=\mathrm{I} \mathrm{L}_{\text {Without Enclosure }}$

$\mathrm{H}_{1}: \mathrm{IL}$ With Enclosure $>I \mathrm{~L}_{\text {Without Enclosure }}$

$H_{2}: I L_{\text {no acoustical foam }}<I L_{\text {with acoustical foam }}$

$\mathrm{H}_{3}$ : $\mathrm{I} \mathrm{L}_{\text {no hole }}>\mathrm{I} \mathrm{L}_{\text {with hole }}$

\section{INTRODUCTION}

Overexposure to noise is one of the biggest problems in the occupational health field today. Hearing loss acquired in the workplace is completely preventable but once hearing damage has occurred it is irreversible. This is why it is important to limit noise exposures to all employees (NIOSH, 2001).

\section{Noise Problems in the Workplace}

According to the National Institute for Occupational Safety and Health (NIOSH) 4 million employees work at noise levels that will cause hearing damage and 30 million employees are exposed to potentially damaging noise each year. Hearing related injuries cost companies approximately $\$ 242.4$ million in disability alone each year and account for $14 \%$ of all occupational injuries (NIOSH, 2011). By reducing noise exposures to employees, companies can lower their workers compensation rates while preserving the quality of life otherwise lost due to impaired hearing. Between 1974 and 1994 the United States Army estimated it saved \$504 
million by reducing hearing loss in combat personnel, a level that did not take into account hearing loss to soldiers who were not in combat.

For these reasons the Occupational Safety and Health Administration (OSHA) has set an action level for noise at $85 \mathrm{dBA}$ averaged over an eight hour shift. At this level a Hearing Conservation Program (HCP) must be put into place. This HCP must provide audiometric testing, personal protective equipment (PPE), training, and recordkeeping. Employers are required to input engineering controls to maintain noise levels below the Permissible Exposure Limit (PEL) of 90 dBA

\section{Approaches to Limiting Employees Exposure to Noise}

There are three major ways to limit employee's exposure to noise: administrative controls, engineering controls, and personal protective equipment (PPE).

\section{$\underline{\text { Administrative Controls }}$}

Administrative controls are ways to limit the amount of employee exposure without changing the process or equipment. The best example of an administrative control is worker rotation, in which employees are cycled through noisy and less noisy tasks during each work shift. With this strategy more employees are exposed but no employees are overexposed. While this approach to noise control limits employee exposure to noise it does not limit the amount of noise produced. This strategy can be attractive but the cost of training employees for multiple tasks and the administrative and supervisory inconvenience job rotation entails limit its application.

\section{Engineering Controls}

Engineering controls include three different means: engineering at the source, engineering at the transmission path, and engineering at the receiver. When selecting a noise intervention there are many considerations that must be taken into account. The two most important are minimizing both the effect of the intervention on production and the cost of implementing the change. 
Engineering at the source is reducing the sound pressure level produced at the source. This requires changing the process or the design of the equipment to achieve lower sound levels within the facility. This is usually difficult to do because changes that reduce noise sometimes reduce efficiency or reliability.

Engineering at the transmission path is used to control noise between the sound source and the employee. There a multiple ways to do this but the most effective is by using a noise enclosure. Noise enclosures are designed to fit around the source, thereby providing noise reduction to the employees in the area.

The final method of engineering controls is to engineer at the receiver. The receiver in most cases is the employee that is affected by the noise source. The most practicable way of engineering at the receiver is enclosing the employee in a sound booth. The major problem with sound booths is they limit employees' mobility because they must remain in the booth to be protected.

\section{$\underline{P P E}$}

Personal protective equipment (PPE) is the final way of limiting employee's exposures. PPE comes in the form of ear muffs and ear plugs. Each set of PPE for noise exposure is designated with a Noise Reduction Rating (NRR), which is intended to tell the user how much noise reduction can be expected from using the hearing protection device.

Ear muffs fit around the outside of the ear and are relatively easy to don and doff, but the employee must make sure they are sealed properly around the ear (Berger et. al, 2000). The major problem with ear muffs is that employees often do not want to wear them because they are cumbersome and uncomfortable.

Ear plugs are the other form of PPE for hearing protection. They are inserted into the employee's ear canal to limit noise exposures. The major problem with earplugs is the same one that limits the effectiveness of ear muffs: employees tend to find them uncomfortable and not wear them. 


\section{Noise Terminology}

Transmission loss (TL), insertion loss (IL), sound absorption, reverberant build up, near field and far field are all important terms when constructing, testing and evaluating the effectiveness a noise enclosure.

\section{Transmission Loss and Noise Reduction}

Transmission loss (TL) is the reduction of the sound pressure level (SPL) due to the insertion of a partition, barrier or enclosure. Noise reduction (NR) is the SPL difference between two spaces separated by a barrier. When designing noise enclosures it is important to know the TL of the enclosure because the highest insertion loss attainable is the TL. The Standard Transmission Class of a material is averaged TL data in1/3 octave bands from 125-4000 Hz (Berger et al.2000). Table 1 shows STC values for typical construction materials. The TL of a hole is zero.

Table 1. Standard Transmission Coefficients of Various Materials

\begin{tabular}{lll}
\hline Material & Weight in lb/ft & STC* \\
\hline Lead 1/64" & 1 & 29 \\
Lead 1/32" & 2 & 35 \\
Plywood 1/4" & 7 & 25 \\
Plywood 3/4" & 2 & 26 \\
Steel 18 Gauge & 2.0 & 31 \\
Steel 16 Gauge & 2.5 & 39 \\
Concrete 4" Thick & 48 & 42 \\
Concrete Block, 6 in & 36 & 40 \\
\hline
\end{tabular}

*average of TL values for the middle octave bands

$\mathrm{TL}_{\text {combined }}$ is the effective $\mathrm{TL}$ of an enclosure that is constructed of multiple materials. It is calculated using: 
$T L_{\text {Combined }}=10 \log \left(\frac{\sum_{1}^{n} S_{i}}{\sum_{1}^{n} S_{i}\left(10^{-T L / 10}\right)}\right), \mathrm{dB}$

Where:

$$
\begin{aligned}
& \mathrm{TL}=\text { transmission loss of each Individual surface } \\
& \mathrm{TL}_{\text {Combined }}=\text { transmission loss combined, } \mathrm{dB}
\end{aligned}
$$

\section{$\underline{\text { Insertion LosS }}$}

IL is defined as the difference in sound levels at a fixed measurement location as taken before and after the noise enclosure is inserted (Berger et al., 2000):

$I L=\left(S P L_{\text {out } 1}-S P L_{\text {out } 2}\right), \mathrm{dB}$

Where:

$S P L_{\text {out } 1}=$ sound pressure level outside the enclosure prior to installation of enclosure $S P L_{\text {out } 2}=$ sound pressure level outside the enclosure after installation of enclosure

The IL of an enclosure can vary due to many different factors. The two most important factors are the material that the enclosure is constructed of and the manner in which the enclosure is constructed. An effective enclosure is generally one constructed of a hard materials that I prevent the noise from penetrating, has minimal penetrations, and has interior surfaces that are covered with sound absorbing materials.

\section{Absorption}

Absorption is an important term when determining the material with which to construct a noise enclosure. Absorption is the ability of a material to absorb sound across all frequencies. To construct an effective enclosure it would be desirable to use a material that has a high STC for the outer shell and then insulate it with a material that is a good absorber. Typically materials that are very thick and porous tend to be much better at absorbing sound than those that are thin and hard.

\section{Predicting the average Sound Absorption of an enclosure}

For calculating the absorption of a specific enclosure the absorptive capabilities of each individual surface inside must be considered. The average absorption is computed as: 


$$
\alpha_{\text {total }}=\frac{\sum_{1}^{n}\left(s_{1} \alpha_{1+} s_{2} \alpha_{2+\ldots} s_{n} \alpha_{n}\right)}{\sum_{1}^{n}\left(s_{1+} s_{2+\ldots}+\ldots s_{n}\right)}
$$

Where:

$$
\begin{aligned}
& \alpha=\text { absorption coefficient of a specified surface } \\
& S=\text { surface area of a specified surface, } \mathrm{ft}^{2} \text { or } \mathrm{m}^{2}
\end{aligned}
$$

Once the total absorption of the noise enclosure has been established, then a room constant(R) can be established for the enclosure:

$$
\begin{aligned}
& R=\frac{S \alpha_{\text {total }}}{1-\alpha_{\text {total }}} \\
& \begin{aligned}
\text { Where: } & \\
\mathrm{R} & =\text { room constant } \mathrm{ft}^{2} \text { or }^{2} \\
\mathrm{~S} & =\text { surface area of the enclosure, } \mathrm{ft}^{2} \text { or }^{2} \\
\alpha_{\text {total }} & =\text { total combined absorption coefficient of the entire noise enclosure }
\end{aligned}
\end{aligned}
$$

\section{Reverberant Build Up}

Reverberant buildup is generated inside a noise enclosure when a sound is produced and either absorbed by the enclosure or transmitted through the enclosure walls. Reverberant buildup plays a large role in the effectiveness of the enclosure. Since sound tends to reflect around the inside of the enclosure until it dissipates or escapes it is always important to take reverberant buildup into design consideration. Reverberant buildup cannot be completely eliminated but it can be reduced by acoustical absorbing material.

\section{Predicting Insertion Loss}

There are few published equations for estimating insertion loss prior to installing the noise enclosure. Equation 5 and Table 2 together provide a simple model whose genesis was unclear for predicting how much IL will be gained depending on the relative surface area covered by insulating materials: 
$I L=T L-X, d B A$

Where:

$$
\begin{aligned}
\mathrm{IL} & =\text { insertion loss, } \mathrm{dBA} \\
\mathrm{TL} & =\text { transmission loss, } \mathrm{dBA} \\
\mathrm{X} & =\text { value off of table } 2, \mathrm{dBA}
\end{aligned}
$$

Table 2. Amount of Sound Reduction Based upon Absorptive Material Inserted into Noise Enclosure

\begin{tabular}{|c|c|}
\hline $\begin{array}{c}\text { Amount of } \\
\text { Absorption }\end{array}$ & $\mathrm{X}, \mathrm{dBA}$ \\
\hline $0 \%$ & 20 \\
\hline $50 \%$ & 15 \\
\hline $100 \%$ & 10 \\
\hline
\end{tabular}

Insertion loss can also be calculated based off of the $\mathrm{TL}_{\text {combined }}$ and $\alpha_{\text {total }}$ of the enclosures construction materials. This equation tends to be more efficient at predicting IL Values for larger enclosures, therefore, comparisons for a small enclosure that is close fitting to the source is predicted to be inaccurate. The equation for doing so is:

$I L=T L_{\text {combined }}+10 \log \left(\alpha_{\text {total }}\right), d B$

\section{Near and Far Field}

A near field is described by Berger et al. as an area close to the sound source where there is "no direct relationship between sound intensity and sound pressure". Thus, there is no predictive model to predict how sound levels will change with locations near the source.

The Noise Manual describes far fields as an area where sound radiates into space without anything to impedance (Berger et. al, 2000). In contrast to near fields, changes in sound levels with distance from the source $(r)$ and other variables using: 


$$
S P L_{i}=L_{w}+10 \log \left[\frac{Q}{4 \pi r^{2}}+\frac{4}{R}\right]+\mathrm{k}, \mathrm{dB}
$$

Where:

$$
\begin{aligned}
S P L_{i} & =\text { sound pressure level, } d B \\
L_{w} & =\text { sound power level referenced to re } 20 \mu P A \\
Q & =\text { directivity factor } \\
r & =\text { distance from sound source } \\
R & =\text { room constant } \\
K & =\text { constant factor }=+10.5 \text { for english units and } 0 \text { for metric units }
\end{aligned}
$$

The directivity factor $(\mathrm{Q})$ use in Equation 8 is based upon the directionality of the sound source due to channeling by adjacent surfaces. Table (3) shows the directivity factors for various channeling conditions.

Table 3. General Directivity Factors Adapted from The Noise Manual.

\begin{tabular}{lc}
\hline Location of source relative to surfaces & Directivity Factor \\
\hline no reflecting surfaces in any direction & 1 \\
$1 / 2$ Sphere reflecting surface on one & 2 \\
$\quad$ side (e.g., the floor) & 4 \\
$\begin{array}{l}\text { 1/4 Sphere at intersection of two } \\
\text { perpendicular surfaces }\end{array}$ & 8 \\
$\begin{array}{l}\text { 1/8 Sphere at the intersection of three } \\
\text { orthogonal surfaces (e.g., a corner } \\
\text { in a room) }\end{array}$ & \\
\hline
\end{tabular}

\section{LITERATURE REVIEW}

Noise enclosures can be an effective way to limit the amount of noise an employee intakes during a work shift. According to Yerges et al, a well-designed and well-insulated noise enclosure can produce IL values in the 30-50 dBA range. Most modern noise enclosures are constructed of several layers designed to reflect and absorb the noise inside the enclosure. Figure 2 shows a cross-section of a noise enclosure wall. 


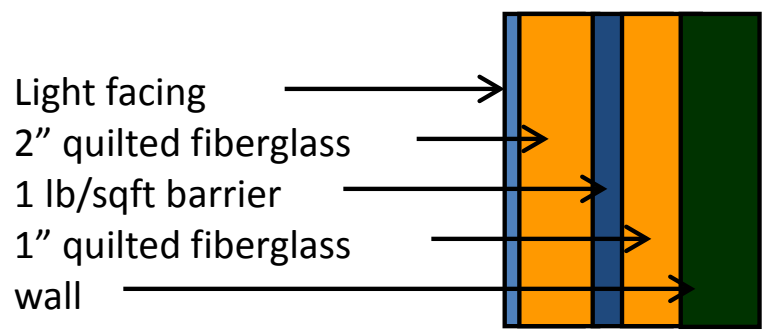

Figure 2. Cross-section of a Typical Noise Enclosure Wall

Arthur Lund (1979) explained the importance of octave band analysis. He said that to construct a successful enclosure you first had to analyze the frequencies to observe which frequencies had the highest SPL values then choose materials that are most effective at reducing SPL values at those frequencies. Some materials are much more effective at lower frequencies than higher frequencies. An example of this is wood absorbs much more sound at lower frequencies while fiber glass tends to absorb more sound at higher frequencies.

\section{Insertion Loss Models}

After a diligent search for Insertion Loss models the only ones found were published by (Oldham and Hilarby, 1991). Oldham and Hilarby investigated noise levels produced by panels of a machine enclosure, most likely a chassis but that is not clear. It is also not clear that the predictive equations they developed are relevant to the case of an enclosure that is more or less isolated from the vibrations produced by the source it encloses. Most importantly, use of their equations required information that is far beyond the scope of this study.

The issue they raised that is relevant to this study is whether a speaker can simulate the noise produced by a machine given that the acceleration characteristics of the two are quite different. They proposed a correction when speakers are used: 
$I L=I L_{m}-20 \log \left(\frac{V_{u}}{V_{e}}\right)$

Where:

$$
\begin{aligned}
& \mathrm{IL}_{\mathrm{m}} \quad \text { = insertion loss measured } \\
& \mathrm{V}_{\mathrm{u}} \quad \text { =accelerometer voltage for unenclosed loudspeaker } \\
& \mathrm{V}_{\mathrm{e}} \quad=\text { accelerometer voltage for the enclosed loudspeaker }
\end{aligned}
$$

Joseph Blanks (1997) studied the IL of a plywood noise enclosure constructed for a portable generator. He found that the models developed by Oldham were accurate in predicting IL for the single and double partitioned walls for his noise enclosure. Blanks also discussed how adding insulating foam in between the two partition walls increased insertion loss. However, this study did not investigate the effectiveness of the enclosure if holes were placed in its walls.

In 2005, Amit Hegde performed a study on how opening size affected the effectiveness of a noise enclosure. As expected, he found that as the opening size of the hole increased, the insertion loss of the enclosure decreased. He noted that a 4 inch diameter hole reduced the effectiveness by $14 \mathrm{~dB}$. He had his microphones located approximately five feet from the noise enclosure and altered their position in accordance with the hole. He also found that when a large hole (64") was placed in the side of the enclosure the enclosure had negative IL values. He theorized that reverberant build up caused this to happen. Since the noise source was somewhat directional and faced the hole, it is more likely that the noise was simply channeled through the holes, thereby increasing noise levels in that direction.

\section{Commercial Enclosures}

Many companies produce noise enclosures with high claimed IL values. For example, enoisecontrol.com (Enoise Control, 2012) offers several different types of enclosures designed for use in an industrial setting. Their enclosures constructed of galvanized steel and lined inside with fiberglass insulation provide a claimed maximum IL of 37-40 dBA, depending on the thickness of the multiple ply wall materials. 
IAC Acoustic Enclosures (IAC Acoustics 2012) design enclosures for specialized machines, such as compressors and generators. They state that their products have a maximum IL of between 15 and $50 \mathrm{dBA}$. However, most noise exposures do not require 30-50 dBA reduction in sound to reduce exposures to less than the OSHA Action Limit.

Since it is expensive to purchase and install commercial enclosures, many avoid them. If it were known that simple, "home-made" enclosures could often provide adequate protection, more companies might choose to install them, thereby reducing noise exposures. 


\section{APPARATUS}

The following noise measurement equipment, test enclosure and test laboratory were used for these two studies.

\section{Measurement Equipment}

To collect the data in this noise study an OROS OR 38 Real-Time Noise Analyzer was used (OROS Inc, Dulles,VA). It has eight input channels for collecting the data and two output channels for producing sound. A computer is interfaced via Ethernet cable to the Noise Analyzer and from there the user can operate the OROS NVGate ${ }^{\odot}$ software, which collects the data from the noise analyzer. Once the analyzer is interfaced with the software the user has the ability to control the front end which consists of all the input channels, calibration settings, microphone coupling, and custom graph generation. The software also has the ability to control the output settings which consists of the noise type generated and the time.

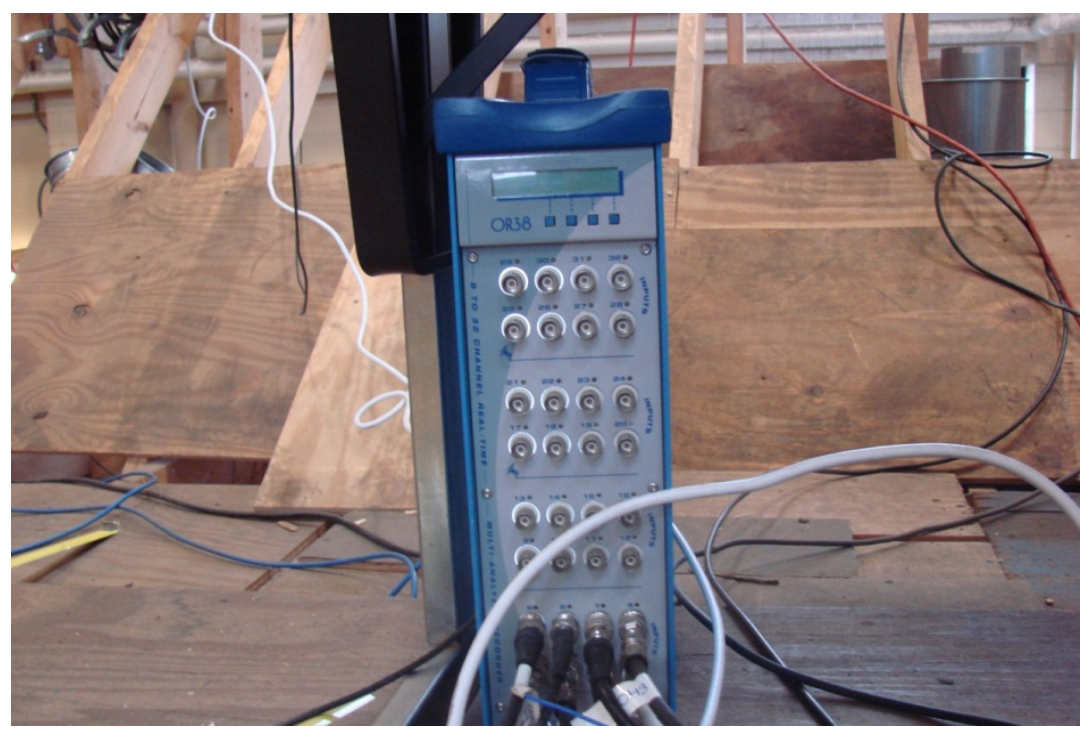

Figure 3. OROS OR38 Noise Analyzer

Sound was generated using an Infinity Primus P162 speaker which has the capability of producing sounds in a frequency range of $49-20,000 \mathrm{Hertz}(\mathrm{Hz})$. The speaker was powered by a noise amplifier that received the signal from the noise analyzer. The speaker was located on a metal pedestal set at a height of $20 \mathrm{~cm}$ and resting on a 1" hard rubber mat that served as the 
floor for the enclosure. The height of the speaker was chosen so that the middle of the speaker coincided with the center of the enclosure when it was in place. Figure 3 shows the speaker, pedestal, and rubber matt.

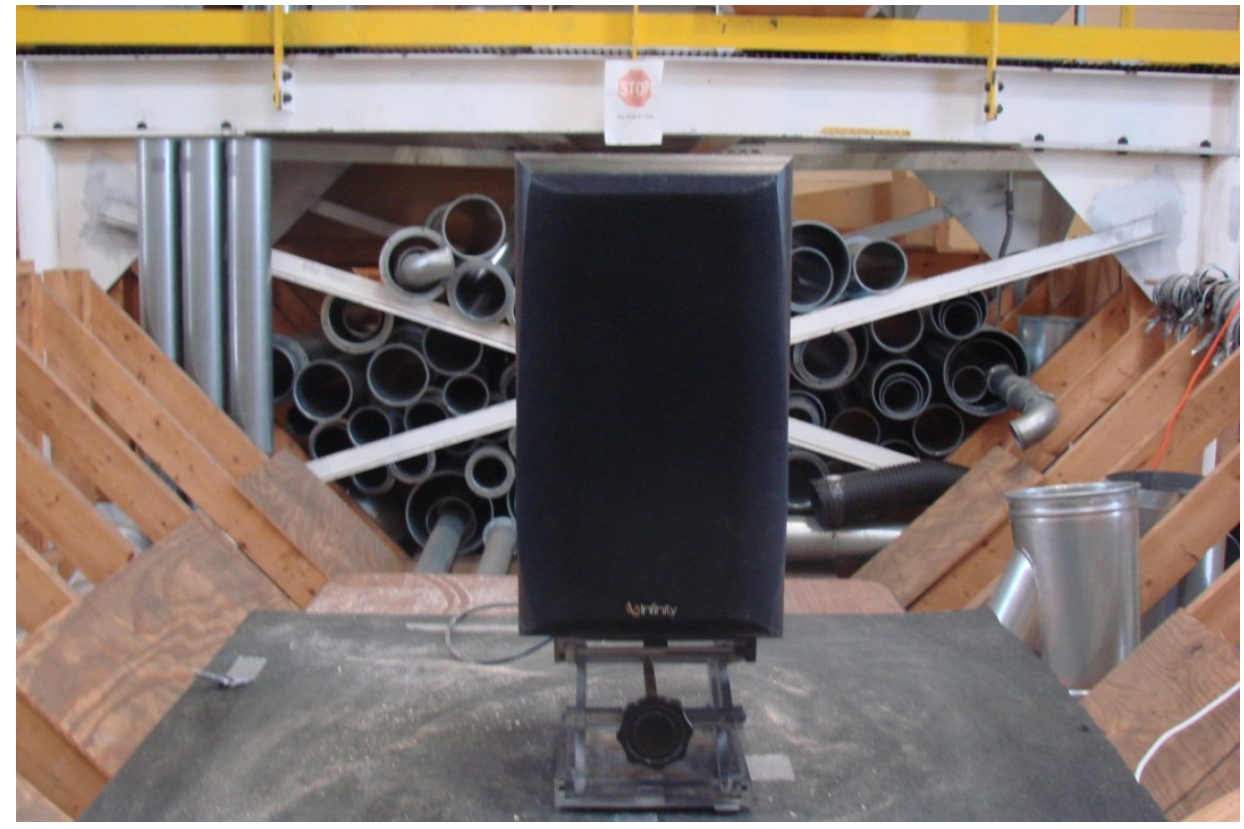

Figure 4. Speaker Location on Metal Pedestal

Sound pressure measurements were taken at the height of the center of the speaker at horizontal distances of four and eight feet from the speaker in each in each of 4 directions such that the a line drawn from the microphones would be normal to each of the 4 sides of the sound enclosure when it was in place (see Figure 1). Eight ICP coupled microphones model numbers 130D20 and 130E20 (PCB Piezotronics ${ }^{\circledR}$, Depew, NY) were used to take the measurements. The source and enclosure were centered on top of a 10' high structure. All of the microphones were above the structure except for two that were off to the left and right of the structure roughly $15^{\prime}$ above the concrete floor. The microphones were secured in place by thin wire and electrical tape affixed to $1 / 8$ " metal rods or wooden posts (see Figure 5 ). This set up was chosen to reduce sound reflections off of the wooden posts that were used to elevate the microphone. 


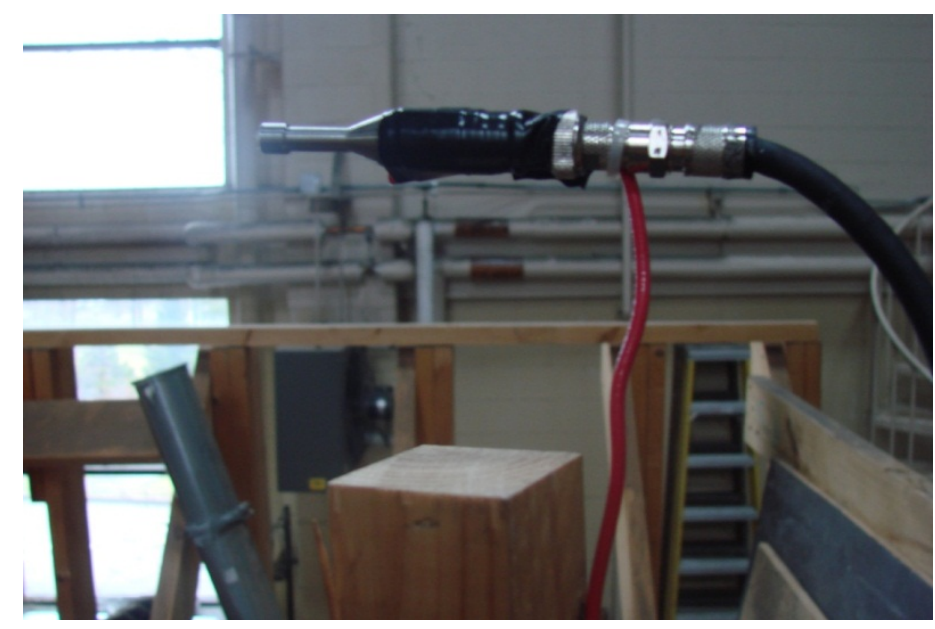

Figure 5. Microphone Attached by a Metal Wire

\section{Test Enclosure}

The dimensions of the noise enclosure were $75 \mathrm{~cm} \times 75 \mathrm{~cm} \times 75 \mathrm{~cm}$. It was constructed of $1 / 2$ " cabinet grade plywood held together by $1 \frac{112 "}{2}$ wood screws. All of the inside edges were sealed with high strength wood caulk (Franklin International, Columbus, Ohio) to reduce transmission loss through gaps. The bottom was open until placed on the rubber mat, which extended 4 inches on each side from the edges of the enclosure. The enclosure rested on the mat but was not sealed to it in any way.

As part of the experiment for some tests $1 \frac{1}{2}$ " egg crate foam acoustical material was added to the enclosure to absorb noise. When Insulation $=0 \%$ no insulation was inside the enclosure. When $50 \%$ insulation was added, it was added to the sides of the enclosure that were facing $0^{\circ}$ and $180^{\circ}$, as well as the top of the enclosure. Finally, when $83 \%$ insulation was added, it was added to all sides of the enclosure except the bottom.

For some tests a hole was cut into one side, first at 2" in diameter and then later enlarged to 4" in diameter for other tests. The holes were made in one side of the enclosure using a drill and a hole saw bit. Hole saw bits are used to make nearly perfectly circular holes. 
Prior to performing the experiments calculations were done using equations 5 and 6 for predicting insertion loss. The equations predicted that the total enclosure would produce ILs of between 5.5 and $22 \mathrm{dBA}$, depending on different test conditions. The results of all the calculations are listed in table 4.

Table 4. Plywood Noise Enclosure Calculations

\begin{tabular}{|c|c|c|c|c|c|}
\hline \multirow[b]{2}{*}{ Test Condition } & \multicolumn{5}{|c|}{ Calculations for plywood noise enclosure } \\
\hline & $\begin{array}{c}\alpha \\
\text { total }\end{array}$ & $\begin{array}{c}\text { Room } \\
\text { Value } \mathrm{m}^{2}\end{array}$ & $\begin{array}{l}T L_{\text {combined }} \\
(\mathrm{dB})\end{array}$ & $\begin{array}{l}\text { IL Based on } \\
\text { Equation } 6\end{array}$ & $\begin{array}{c}\text { Simple IL based } \\
\text { on Equation } 5\end{array}$ \\
\hline Enclosure $0 \%$ insulation & 0.15 & 0.50 & 25.5 & 17.3 & 5.5 \\
\hline Enclosure $50 \%$ insulation & 0.33 & 1.39 & 25.5 & 20.7 & 10.5 \\
\hline Enclosure $83 \%$ insulation & 0.45 & 2.30 & 25.5 & 22.0 & 13 \\
\hline $\begin{array}{l}\text { Enclosure } 2 " \text { hole } \\
0 \% \text { insulation }\end{array}$ & 0.15 & $x$ & 24.5 & 16.3 & $x$ \\
\hline $\begin{array}{l}\text { Enclosure } 2 " \text { hole } \\
100 \% \text { insulation }\end{array}$ & 0.45 & $x$ & 24.5 & 21.03 & $x$ \\
\hline $\begin{array}{l}\text { Enclosure } 4 " \text { hole } \\
0 \% \text { insulation }\end{array}$ & 0.15 & $x$ & 22.5 & 14.3 & $x$ \\
\hline $\begin{array}{l}\text { Enclosure } 4 " \text { hole } \\
100 \% \text { insulation }\end{array}$ & 0.45 & $X$ & 22.5 & 19.0 & $X$ \\
\hline
\end{tabular}

\section{Test Laboratory}

The experiment was setup within Mineral Resources Building 157 at West Virginia University. The dimensions of the room were $70^{\prime} \times 50^{\prime} \times 46^{\prime}$. The location was selected because it was fairly open and had few reflective surfaces near the locations of the microphones. As shown in figure 6 , the only side where there were reflective surfaces near the microphones was $180^{\circ}$ from the direction the speaker was facing.

On days when testing was taking place all other noise sources inside the room were turned off to prevent any confounding from other noise sources and only the people performing the experiment were in the lab. 


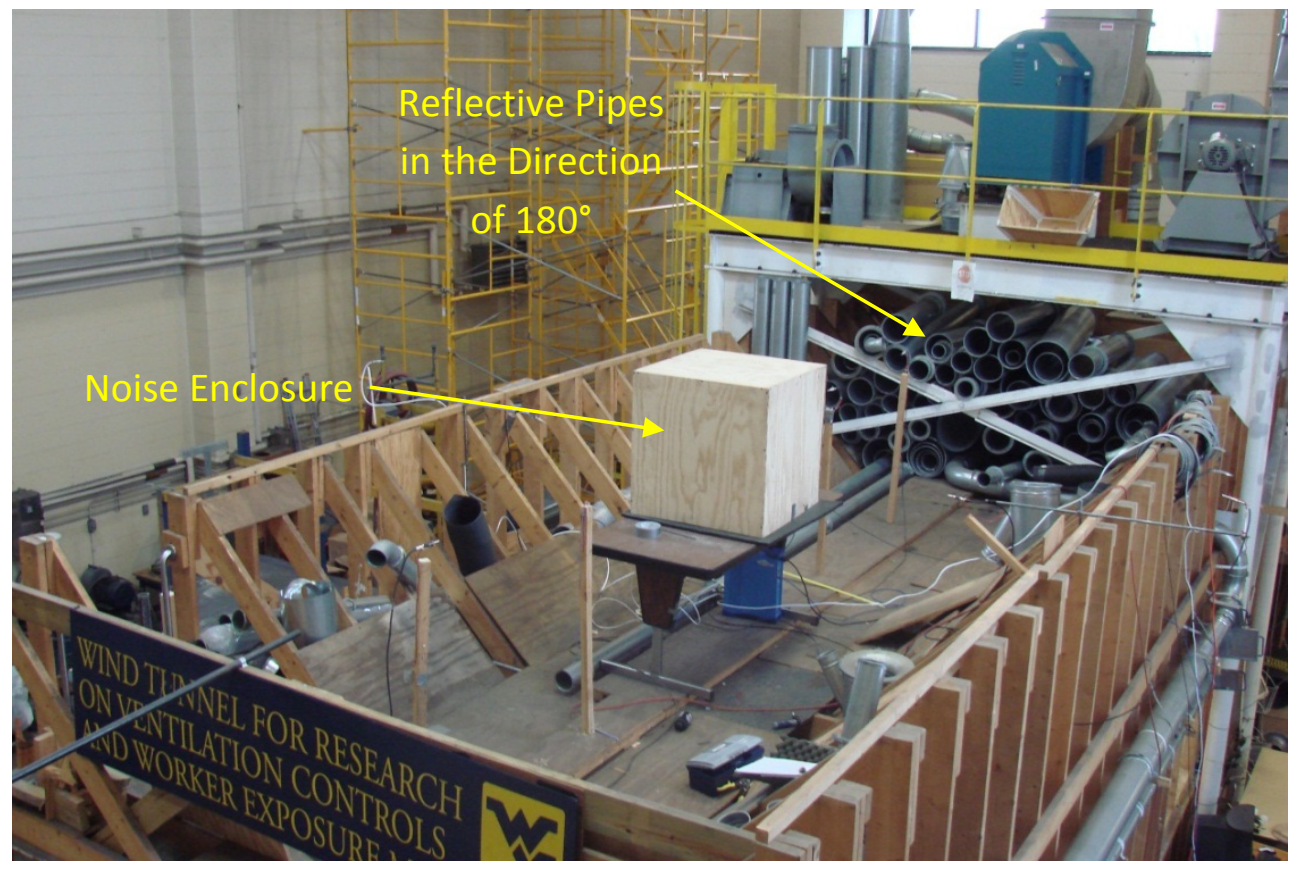

Figure 6. Location of the Enclosure within the Room

\section{MethodS}

\section{Preparing the Microphones}

Prior to each day of testing the microphone positions were checked with a measuring tape.

After that all microphones were calibrated in place using a Quest QC-10 calibrator (3M,Oconomowoc, WI)and NVGATE Software.

\section{Baseline Measurement}

Each day after microphone calibrations were performed a baseline measurement was taken without the noise enclosure. This served as the test condition of no enclosure for that day to allow computation of IL values for conditions tested that day. 


\section{Enclosure Testing}

The enclosure was placed over the sound source and lined up with pre-set marks on the rubber matt to ensure it was centered properly. Each set of noise measurements were taken and logged for 30 seconds using the $1 / \mathrm{N}$ Octave setting inside the NVGate ${ }^{\circledR}$ software. A different test condition was then set up and another trial was run until all the test conditions and replications for that day were completed. Table 5 shows all of the tests and replications that were performed in the study.

Table 5. Test Conditions

\begin{tabular}{lcccc}
\hline $\begin{array}{c}\text { Test } \\
\text { Condition }\end{array}$ & Replications & Insulation (\%) & Hole Diameter (") & $\begin{array}{c}\text { Hole } \\
\text { Direction( }\end{array}$ \\
\hline & & Study 1 & \\
1 & 4 & 0 & 0 & 0 \\
2 & 4 & 50 & 0 & 0 \\
3 & 4 & 83 & 0 & 0 \\
& & & & \\
4 & 4 & Study 2 & & 0 \\
5 & 4 & 0 & 2 & 180 \\
6 & 4 & 0 & 2 & 0 \\
7 & 4 & 100 & 2 & 180 \\
8 & 4 & 100 & 2 & 0 \\
9 & 4 & 0 & 4 & 0 \\
10 & 4 & 0 & 4 & 180 \\
11 & 4 & 100 & 4 & 4 \\
\hline
\end{tabular}

\section{Data Analysis}

For every trial that was run, the data for each individual microphone was saved within the NVGATE software. After that, the data was exported to Microsoft EXCEL 2010 for a preliminary analysis. This analysis included computing dBA values from the octave band data using Equations 9 and 10: 
A-Scale Weighting $=\frac{12200^{2} \cdot \mathrm{f}^{4}}{\left(\mathrm{f}^{2}+20.6^{2}\right) \sqrt{\left(\mathrm{f}^{2}+107.7^{2}\right) \cdot\left(\mathrm{f}^{2}+737.9^{2}\right) \cdot\left(\mathrm{f}^{2}+12200^{2}\right)}}$

$f=$ frequency

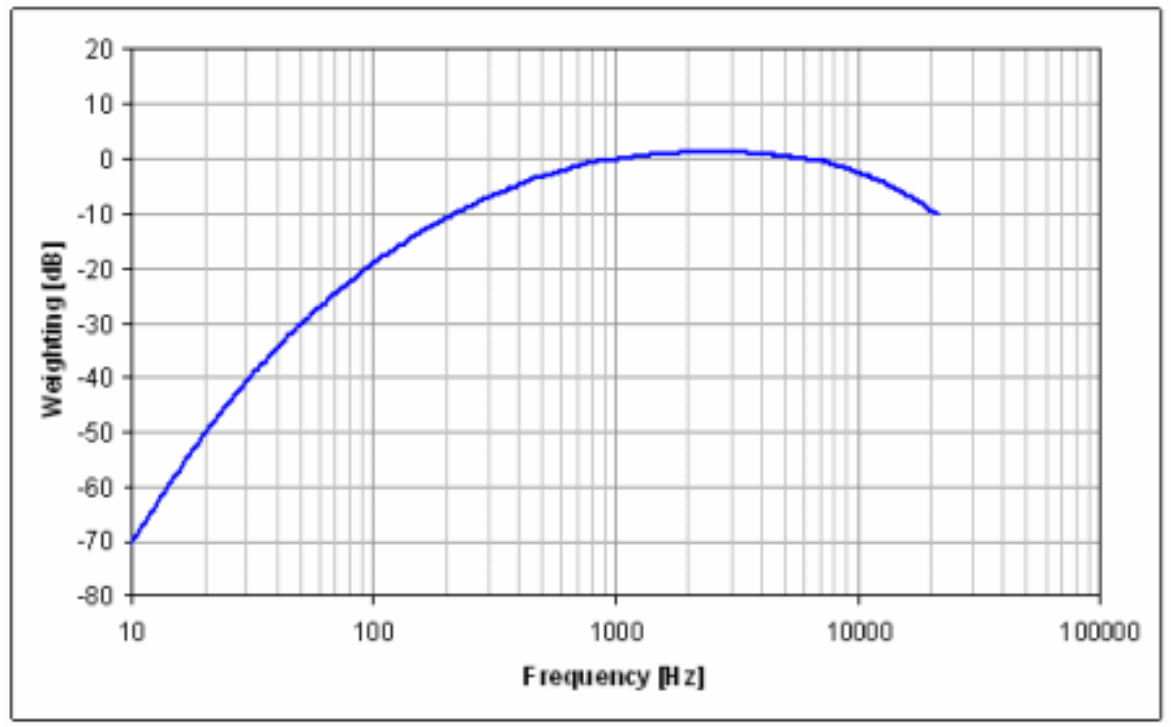

Figure 7. Graph of Standard A-weighting

$\mathrm{SPL}=10 \log _{10}\left(\sum_{8}^{1} 10^{\frac{S P l_{1}-A w t 1}{10}}\right)$

The average SPL for each test for each microphone was paired with the no enclosure data from that day in order for IL to be determined (see Equation 9). These data were then analyzed using Data Desk 6.3 (Data Description Inc., Ithaca New York).

\section{Results ANd Discussion fOR StUdy ONe}

Study One focused on the effect of Insulation, Microphone Location, and Distance on the IL of the noise enclosure. Table 6 shows the $\mathrm{SP}_{\mathrm{i}}$ values for when there was no enclosure present and when the enclosure with $0 \%$ insulation was placed over the sound source. This is important because IL is determined by comparing the $\mathrm{SPL}_{\mathrm{i}}$ values before and after the enclosure was added. 
Table 6. $\mathrm{SPL}_{\mathrm{i}}$ Values in $\mathrm{dBA}$ of No Enclosure and Enclosure in all Directions

\begin{tabular}{|c|c|c|c|c|c|c|c|c|}
\hline \multicolumn{9}{|c|}{ Microphone Location } \\
\hline & \multicolumn{2}{|c|}{$0^{\circ}$} & \multicolumn{2}{|c|}{$90^{\circ}$} & \multicolumn{2}{|c|}{$180^{\circ}$} & \multicolumn{2}{|c|}{$270^{\circ}$} \\
\hline Replication & $4 \mathrm{Ft}$ & $8 \mathrm{Ft}$ & $4 \mathrm{Ft}$ & $8 \mathrm{Ft}$ & $4 \mathrm{Ft}$ & $8 \mathrm{Ft}$ & $4 \mathrm{Ft}$ & $8 \mathrm{Ft}$ \\
\hline \multicolumn{9}{|c|}{ No enclosure } \\
\hline 1 & 95.9 & 87.4 & 87.5 & 81.9 & 86.2 & 83.4 & 87.4 & 82.3 \\
\hline 2 & 95.9 & 87.3 & 87.3 & 81.8 & 86.2 & 83.4 & 87.5 & 82.3 \\
\hline 3 & 95.7 & 87.3 & 87.2 & 81.6 & 86.1 & 83.2 & 87.6 & 82.2 \\
\hline 4 & 95.8 & 87.3 & 87.3 & 81.7 & 86.3 & 83.1 & 87.6 & 82.3 \\
\hline Average & 95.8 & 87.3 & 87.3 & 81.8 & 86.2 & 83.3 & 87.5 & 82.3 \\
\hline \multicolumn{9}{|c|}{ With Enclosure } \\
\hline 1 & 88.1 & 81.1 & 79.2 & 73.9 & 83.1 & 76.7 & 79.3 & 74.5 \\
\hline 2 & 87.4 & 80.0 & 81.1 & 75.8 & 82.5 & 77.0 & 79.2 & 74.9 \\
\hline 3 & 87.3 & 79.9 & 81.0 & 75.6 & 82.5 & 76.6 & 78.6 & 74.7 \\
\hline 4 & 87.5 & 80.0 & 80.9 & 75.4 & 82.3 & 76.5 & 78.5 & 74.2 \\
\hline Average & 87.6 & 80.3 & 80.6 & 75.2 & 82.6 & 76.7 & 78.9 & 74.6 \\
\hline
\end{tabular}

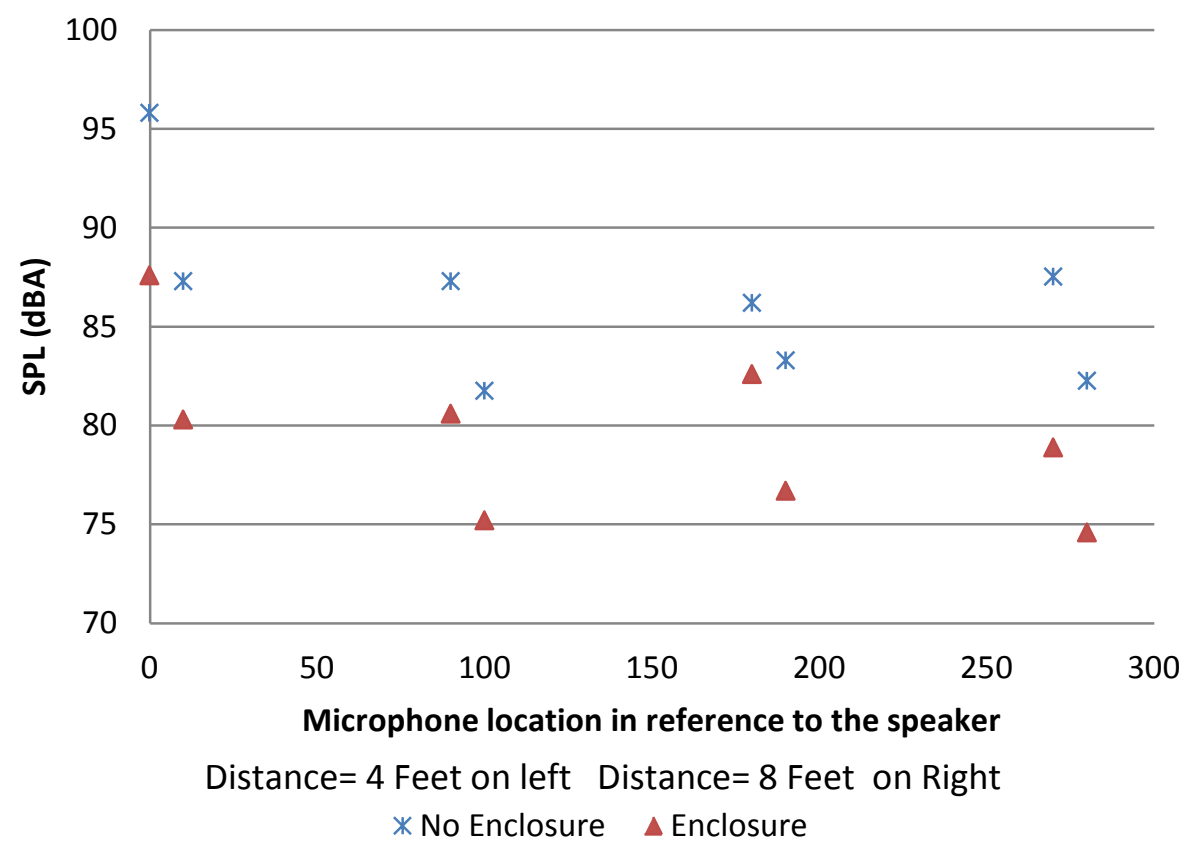

Figure $8 . \mathrm{SPL}_{i}$ values at a distance of 4 and 8 feet from the sound source. 
Figure 8 shows the $S P L_{i}$ values for Enclosure and No Enclosure at distances of 4 feet and 8 feet. As predicted the $S P L_{i}$ values were much higher at 4 feet than at 8 feet because the locations were closer to the sound source. This figure also shows the sound source was somewhat directional without the enclosure in place. SPL values measured in the direction the speaker faced were always higher than in the other directions at the same distance. The difference between No Enclosure and Enclosure was between 4 and $8 \mathrm{dBA}$ except in the direction $180^{\circ}$ from the direction the speaker faced at a distance of 4 feet. At this location the difference was only 2.9 dBA. Apparently, the directionality of the source mattered even when the enclosure was in place.

Table 7. Average Insertion Loss of Noise Enclosure with Varying amounts of Insulation

\begin{tabular}{|c|c|c|c|c|c|c|}
\hline & & $\begin{array}{l}\text { Mean } \\
(\mathrm{dBA})\end{array}$ & $\begin{array}{l}\text { Mean } \\
(\mathrm{dBA})\end{array}$ & $\begin{array}{l}\text { Mean } \\
\text { (dBA) }\end{array}$ & StdD & StdD \\
\hline Direction & Insulation & Dist $=4^{\prime}$ & Dist $=8$ & Avg & Dist $=4^{\prime}$ & Dist $=8$ \\
\hline \multicolumn{7}{|c|}{ Enclosure $0 \%$ insulation } \\
\hline $0^{\circ}$ & $0 \%$ & 8.3 & 7.1 & 7.7 & 0.4 & 0.5 \\
\hline $90^{\circ}$ & $0 \%$ & 6.7 & 6.5 & 6.6 & 1.0 & 0.9 \\
\hline $180^{\circ}$ & $0 \%$ & 3.6 & 6.5 & 5.1 & 0.3 & 0.2 \\
\hline $270^{\circ}$ & $0 \%$ & 8.6 & 7.7 & 8.2 & 0.5 & 0.3 \\
\hline average & $0 \%$ & 6.8 & 7.0 & 6.9 & 0.6 & 0.5 \\
\hline \multicolumn{7}{|c|}{ Enclosure $50 \%$ insulation } \\
\hline $0^{\circ}$ & $50 \%$ & 11.9 & 10.4 & 11.1 & 0.3 & 0.4 \\
\hline $90^{\circ}$ & $50 \%$ & 11.2 & 9.9 & 10.5 & 0.2 & 0.3 \\
\hline $180^{\circ}$ & $50 \%$ & 6.7 & 9.7 & 8.2 & 0.2 & 0.2 \\
\hline $270^{\circ}$ & $50 \%$ & 11.4 & 10.4 & 10.9 & 0.3 & 0.1 \\
\hline average & $50 \%$ & 10.3 & 10.1 & 10.2 & 0.2 & 0.3 \\
\hline \multicolumn{7}{|c|}{ Enclosure $100 \%$ insulation } \\
\hline $0^{\circ}$ & $100 \%$ & 13.2 & 12.1 & 12.6 & 0.3 & 0.2 \\
\hline $90^{\circ}$ & $100 \%$ & 11.8 & 10.6 & 11.2 & 0.7 & 0.4 \\
\hline $180^{\circ}$ & $100 \%$ & 7.1 & 9.7 & 8.4 & 0.2 & 0.2 \\
\hline $270^{\circ}$ & $100 \%$ & 12.0 & 11.4 & 11.7 & 0.3 & 0.4 \\
\hline average & $100 \%$ & 11.0 & 11.0 & 11.0 & 0.4 & 0.3 \\
\hline \multicolumn{7}{|c|}{ All Enclosure Data } \\
\hline $0^{\circ}$ & all & 11.1 & 9.8 & 10.5 & 0.3 & 0.4 \\
\hline $90^{\circ}$ & all & 9.9 & 9.0 & 9.5 & 0.7 & 0.5 \\
\hline $180^{\circ}$ & all & 5.8 & 8.6 & 7.2 & 0.2 & 0.2 \\
\hline $270^{\circ}$ & all & 10.7 & 9.8 & 10.3 & 0.4 & 0.3 \\
\hline average & all & 9.4 & 9.3 & 9.4 & 0.4 & 0.3 \\
\hline
\end{tabular}


The results in Table 7 and Figure 9 show that the overall means of IL for all conditions of Insulation varied by only $0.1 \mathrm{dBA}$ at distances of both 4 and 8 feet. At a measurement distance 4 feet the insertion loss (IL) averaged over all conditions where hole diameter is 0 " was $9.4 \mathrm{dBA}$ and at 8 feet the average IL was 9.3 dBA. When the level of Insulation was considered (0\%, $50 \%$, and $83 \%$ ), the values of IL at 4 and 8 feet averaged over all 4 directions varied from 0 to $0.2 \mathrm{dBA}$. Prior to the experiment, it was expected that the IL values at 4 and 8 feet would be the same under all conditions. This appeared to be true in the directions of $0^{\circ}, 90^{\circ}$, and $270^{\circ}$, where the values differed by less than $1.3 \mathrm{dBA}$. However, in the direction of $180^{\circ}$ the difference was $2.8 \mathrm{dBA}$.

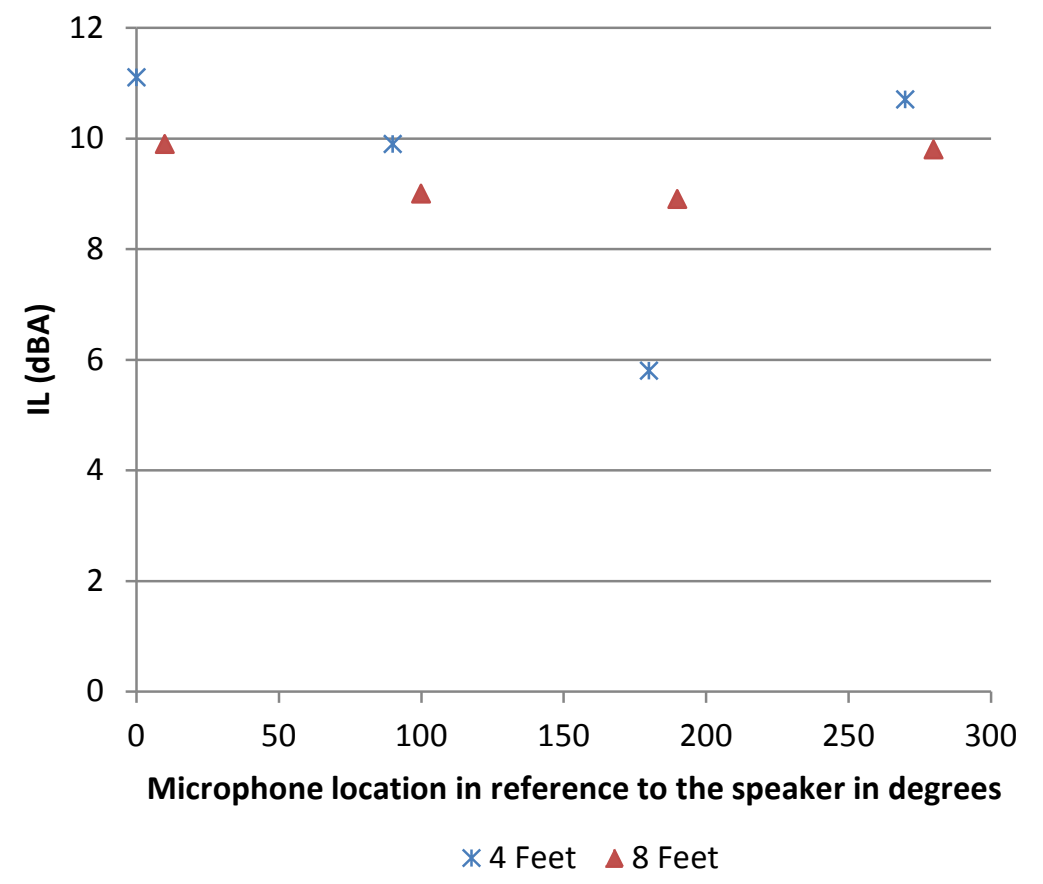

Figure 9. Average IL values with all levels of insulation 


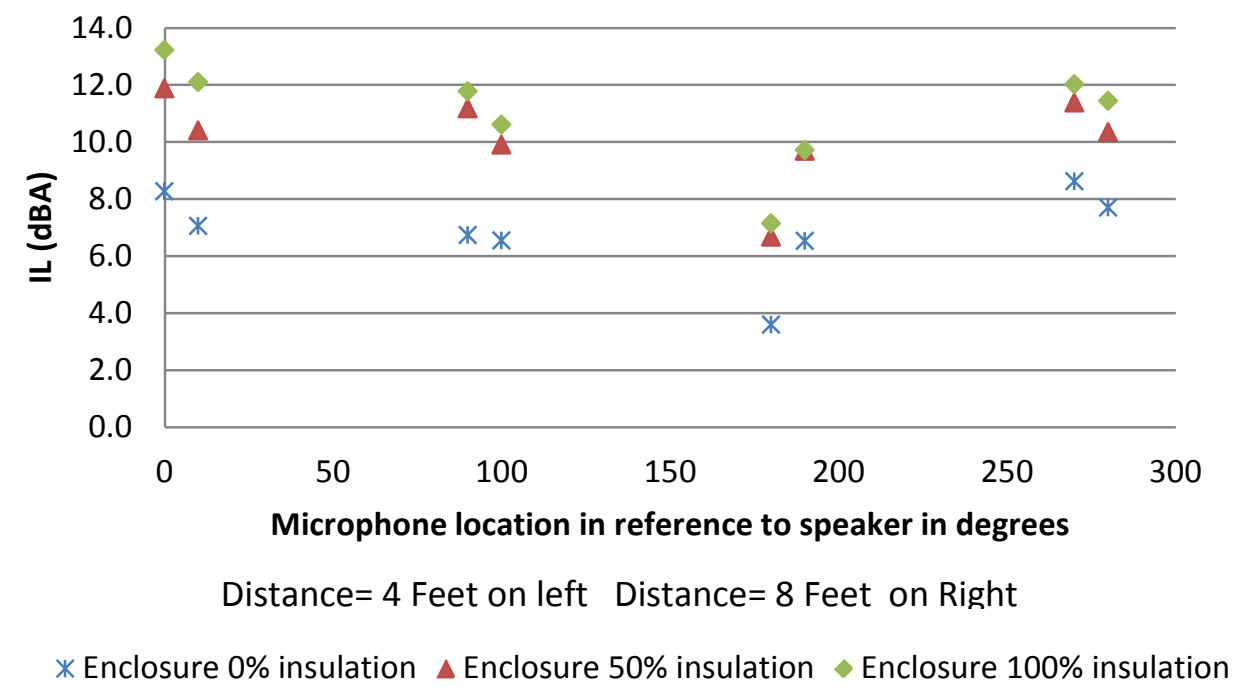

Figure 10. Effects of Insulation on IL

As shown in Figure 10, the IL values at Microphone Location $=180^{\circ}$ were nearly all lower than corresponding values of IL for all amounts of insulation and for both distances. Likewise, the values of IL for Insulation $=50 \%$ and Insulation $=83 \%$ were consistently lower than IL values for Insulation=0\%, as one would expect. A possible interactive effect between Microphone Location and Distance is suggested by the fact that the IL values for Distance $=4$ feet are less than $1.3 \mathrm{dBA}$ for all Insulation and Location values except Location $=180^{\circ}$. For the latter, average difference in IL for 8 feet is $2.8 \mathrm{dBA}$ higher than the average IL for 4 feet. 
Table 8. Comparison of predicted and actual IL values based upon

$$
I L=T L-X
$$

\begin{tabular}{lcc}
\hline Amount of Insulation & $\mathrm{TL}-\mathrm{X}, \mathrm{dBA}$ & Actual IL dBA \\
\hline $0 \%$ & 5.5 & 6.9 \\
$50 \%$ & 10.5 & 10.2 \\
$83 \%$ & 13 & 11.0 \\
\hline
\end{tabular}

Table 8 shows the comparison of the predicted IL values to the actual IL values. Equation 6 proved to be reasonable accurate, especially at $0 \%$ and $50 \%$ insulation.

Table 9. ANOVA Statistics on Study One

\begin{tabular}{lccccc}
\hline Source & $\begin{array}{c}\text { Degrees } \\
\text { Freedom }\end{array}$ & $\begin{array}{c}\text { Sums of } \\
\text { Squares }\end{array}$ & $\begin{array}{c}\text { Mean } \\
\text { Square }\end{array}$ & F-ratio & Probability \\
\hline Constant & 1 & 8403 & 8403 & 43605 & ? 0.0001 \\
Insulation & 2 & 304 & 152 & 789 & ? 0.0001 \\
Distance & 1 & 0.043 & 0.043 & 0.225 & 0.637 \\
Mic location & 3 & 158 & 52 & 274 & $? 0.0001$ \\
Distance* Mic Location & 3 & 67.3 & 22.4 & 116 & ? 0.0001 \\
Insulation*Distance & 2 & 0.520 & 0.260 & 1.349 & 0.266 \\
Insulation* Mic Location & 6 & 9.02 & 1.50 & 7.802 & ? 0.0001 \\
Error & 78 & 15 & 0.193 & & \\
Total & 95 & 555.129 & & & \\
\hline
\end{tabular}

\section{Statistical Analysis}

The ANOVA for Study One (see Table 9) indicate that Insulation and Microphone Location were highly significant $(p<0.0001)$ while Distance was not $(p>0.1)$. As shown in Table 9, Insulation accounted for $55 \%$ of the total sum of squares, while Microphone Location accounted for $29 \%$.

The interaction of Microphone Location with Distance and with Insulation were both highly significant $(p<0.01 \%)$. Consider both the main effect and the interactions Microphone Location accounted for $41 \%$ of the sum of squares when determining the IL values for the enclosure. 
Table 10. Scheffe Post Hoc on Amount of Insulation

\begin{tabular}{lrrr}
\hline $\begin{array}{c}\text { Amount of } \\
\text { Insulation }\end{array}$ & $\begin{array}{r}\text { Difference } \\
\text { in IL (dBA) }\end{array}$ & std. err. & Probability \\
\hline $50-0$ & 3.3 & 0.11 & 0 \\
$83-0$ & 4.1 & 0.11 & 0 \\
$83-50$ & 0.81 & 0.11 & $1.03 \mathrm{E}-09$ \\
\hline
\end{tabular}

The Scheffe Post Hoc Test on the different amounts of insulation added to the enclosure (see Table 10) showed that there was a significant difference in IL based on different levels of Insulation. However, the mean overall difference between adding $50 \%$ insulation and $83 \%$ insulation to the enclosure was only $0.8 \mathrm{dBA}$. These results show that the majority of the IL that was gained by the enclosure was when the insulation was increased from $0 \%$ to $50 \%$.

Table 11. Scheffe Post Hoc Test on Microphone Location

\begin{tabular}{lccc}
\hline $\begin{array}{c}\text { Microphone } \\
\text { Location }\end{array}$ & $\begin{array}{c}\text { Difference } \\
\text { in IL (dBA) }\end{array}$ & $\begin{array}{c}\text { Standard } \\
\text { Error }\end{array}$ & Probability \\
\hline $90-0$ & -1.0 & 0.53 & 0.319 \\
$180-0$ & -2.6 & 0.53 & $5.68 \mathrm{E}-04^{*}$ \\
$180-90$ & -1.6 & 0.53 & 0.050 \\
$270-0$ & 0.50 & 0.53 & 0.828898 \\
$270-90$ & 1.5 & 0.53 & 0.063954 \\
$270-180$ & 3.1 & 0.53 & $5.34 \mathrm{E}-05^{*}$ \\
\hline
\end{tabular}

The Scheffe Post Hoc Test on Microphone Location (Table 11) indicated that there was a significant difference between IL results for Microphone Locations at $0^{\circ}$ and $180^{\circ}$ and for Microphone Locations at $270^{\circ}$ and $180^{\circ}$. There was also a large difference between $90^{\circ}$ and $180^{\circ}$ but it was not deemed statistically significant $(p>.05)$. The large difference between all other Microphone Locations and the Microphone Location of $180^{\circ}$ was anticipated because the $\mathrm{SPL}_{\mathrm{i}}$ values for $180^{\circ}$ shown in Table 6 were much lower than in all other directions. 
Table 12. Scheffe Post Hoc on the Interactive effect of Mic Location and Distance

\begin{tabular}{cccc}
\hline $\begin{array}{c}\text { Mic Loc,Dist- } \\
\text { Mic Loc,Dist }\end{array}$ & $\begin{array}{c}\text { Difference } \\
\text { in IL (dBA) }\end{array}$ & std. err. & Probability \\
\hline $0,8-0,4$ & -1.29 & 0.18 & $1.14 \mathrm{E}-08$ \\
$90,4-0,4$ & -1.22 & 0.18 & $5.13 \mathrm{E}-08$ \\
$90,4-0,8$ & 0.06 & 0.18 & 0.98832 \\
$90,8-0,4$ & -2.10 & 0.18 & 0 \\
$90,8-0,8$ & -0.81 & 0.18 & $3.61 \mathrm{E}-04$ \\
$90,8-90,4$ & -0.88 & 0.18 & $1.03 \mathrm{E}-04$ \\
$180,4-0,4$ & -5.32 & 0.18 & $0^{*}$ \\
$180,4-0,8$ & -4.03 & 0.18 & $0^{*}$ \\
$180,4-90,4$ & -4.10 & 0.18 & $0^{*}$ \\
$180,4-90,8$ & -3.22 & 0.18 & $0^{*}$ \\
$180,8-0,4$ & -2.48 & 0.18 & 0 \\
$180,8-0,8$ & -1.19 & 0.18 & $1.15 \mathrm{E}-07$ \\
$180,8-90,4$ & -1.25 & 0.18 & $2.59 \mathrm{E}-08$ \\
$180,8-90,8$ & -0.38 & 0.18 & 0.231632 \\
$180,8-180,4$ & 2.84 & 0.18 & 0 \\
$270,4-0,4$ & -0.45 & 0.18 & 0.112616 \\
$270,4-0,8$ & 0.84 & 0.18 & $2.08 \mathrm{E}-04$ \\
$270,4-90,4$ & 0.78 & 0.18 & $7.05 \mathrm{E}-04$ \\
$270,4-90,8$ & 1.66 & 0.18 & $1.55 \mathrm{E}-12$ \\
$270,4-180,4$ & 4.87 & 0.18 & $0 *$ \\
$270,4-180,8$ & 2.03 & 0.18 & $2.22 \mathrm{E}-16$ \\
$270,8-0,4$ & -1.29 & 0.18 & $9.98 \mathrm{E}-09$ \\
$270,8-0,8$ & -0.01 & 0.18 & 0.999991 \\
$270,8-90,4$ & -0.07 & 0.18 & 0.985031 \\
$270,8-90,8$ & 0.81 & 0.18 & $4.03 \mathrm{E}-04$ \\
$270,8-180,4$ & 4.03 & 0.18 & $0^{*}$ \\
$270,8-180,8$ & 1.18 & 0.18 & $1.31 \mathrm{E}-07$ \\
$270,8-270,4$ & -0.85 & 0.18 & $1.86 \mathrm{E}-04$ \\
\hline
\end{tabular}

*Results that were statistically significant $(p<1 \%)$ and difference was greater than $3 \mathrm{dBA}$

The Scheffe Post Hoc test for the interaction between Microphone Location and Distance (see Table 12) show that most of the pairs of Microphone Location and Distance were statistically significant $(p<0.01)$. However, some of the differences in results that were statistically significant were as low as $0.4 \mathrm{dBA}$. As a practical matter, differences less than $3 \mathrm{dBA}$ may be considered unimportant. 


\section{CONCLUSIONS FOR STUdY ONE}

For Study One the most important conclusion is that the noise enclosure was effective for many applications since it produced an average IL of at least $6.9 \mathrm{dBA}$ even when there was no insulation in the enclosure and 10.2 and $11.0 \mathrm{dBA}$ when Insulation was $50 \%$ and $83 \%$, respectively. Insulation helped but diminishing returns were evident at Insulation $=83 \%$.

The study also showed that the Microphone Location had a significant effect on the amount of IL the enclosure produced. In particular, when the direction was such that Microphone Location $=180^{\circ} \mathrm{IL}$ values were much lower than for measurements taken on other sides of the enclosure.

The final conclusion drawn from Study One was that Distance did not have a significant effect on the amount of IL the noise enclosure produced, as expected. 


\section{ResUltS AND Discussion for StUdy two}

Study Two focused on the effect of Hole Diameter and Hole Direction on the IL of the noise enclosure. Other variables such as Distance, Microphone Location and Insulation also were used as test variables for this study.

Table 13. Insertion Loss of noise enclosure with 2" hole

\begin{tabular}{|c|c|c|c|c|c|c|c|c|}
\hline & & & & Mean & Mean & Mean & StdD & StdD \\
\hline Direction & $\begin{array}{c}\text { Hole } \\
\text { Diamete }\end{array}$ & $\begin{array}{c}\text { Hole } \\
\text { direction }\end{array}$ & Insulation & Dist $=4^{\prime}$ & $\underline{\text { Dist }=8}$ & $\underline{A v g}$ & $\underline{\text { Dist }=4}$ & Dist $=81$ \\
\hline \multicolumn{9}{|c|}{ Enclosure with $2 "$ hole. $0 \%$ insulation. Hole facing $0^{\circ}$} \\
\hline $0^{\circ}$ & $2^{\prime \prime}$ & 0 & $0 \%$ & 10.1 & 5.9 & 8.0 & 0.2 & 0.4 \\
\hline $90^{\circ}$ & $2^{\prime \prime}$ & 0 & $0 \%$ & 6.5 & 6.1 & 6.3 & 0.3 & 0.1 \\
\hline $180^{\circ}$ & $2^{\prime \prime}$ & 0 & $0 \%$ & 3.6 & 4.5 & 4.1 & 0.2 & 0.2 \\
\hline $270^{\circ}$ & $2^{\prime \prime}$ & 0 & $0 \%$ & 8.8 & 5.2 & 7.0 & 0.2 & 0.2 \\
\hline Average & $2^{\prime \prime}$ & 0 & $0 \%$ & 7.3 & 5.4 & 6.4 & 0.2 & 0.2 \\
\hline \multicolumn{9}{|c|}{ Enclosure with $2 "$ hole. $0 \%$ insulation. Hole Facing $180^{\circ}$} \\
\hline $0^{\circ}$ & $2^{\prime \prime}$ & 180 & $0 \%$ & 11.0 & 7.0 & 9.0 & 0.2 & 0.3 \\
\hline $90^{\circ}$ & $2^{\prime \prime}$ & 180 & $0 \%$ & 5.5 & 5.7 & 5.6 & 0.5 & 0.6 \\
\hline $180^{\circ}$ & $2^{\prime \prime}$ & 180 & $0 \%$ & 1.9 & 3.0 & 2.4 & 0.5 & 0.4 \\
\hline $270^{\circ}$ & $2^{\prime \prime}$ & 180 & $0 \%$ & 8.8 & 5.0 & 6.9 & 0.9 & 1.0 \\
\hline Average & $2^{\prime \prime}$ & 180 & $0 \%$ & 6.8 & 5.2 & 6.0 & 0.5 & 0.6 \\
\hline \multicolumn{9}{|c|}{ Enclosure with $2 "$ hole. $83 \%$ insulation. Hole facing $0^{\circ}$} \\
\hline $0^{\circ}$ & $2 "$ & 0 & $83 \%$ & 14.2 & 10.6 & 12.4 & 0.6 & 0.5 \\
\hline $90^{\circ}$ & $2^{\prime \prime}$ & 0 & $83 \%$ & 10.3 & 10.1 & 10.2 & 0.2 & 0.3 \\
\hline $180^{\circ}$ & $2 "$ & 0 & $83 \%$ & 7.8 & 8.0 & 7.9 & 0.3 & 0.4 \\
\hline $270^{\circ}$ & $2^{\prime \prime}$ & 0 & $83 \%$ & 12.4 & 9.5 & 11.0 & 0.3 & 0.3 \\
\hline Average & $2 "$ & 0 & $83 \%$ & 11.2 & 9.6 & 10.4 & 0.3 & 0.4 \\
\hline \multicolumn{9}{|c|}{ Enclosure with $2 "$ hole. $83 \%$ insulation. Hole facing $180^{\circ}$} \\
\hline $0^{\circ}$ & $2 "$ & 180 & $83 \%$ & 15.5 & 11.6 & 13.6 & 0.1 & 0.2 \\
\hline $90^{\circ}$ & $2^{\prime \prime}$ & 180 & $83 \%$ & 9.5 & 9.3 & 9.4 & 0.5 & 0.9 \\
\hline $180^{\circ}$ & $2^{\prime \prime}$ & 180 & $83 \%$ & 5.8 & 6.8 & 6.3 & 0.5 & 0.3 \\
\hline $270^{\circ}$ & $2 "$ & 180 & $83 \%$ & 12.4 & 8.7 & 10.5 & 0.7 & 1.2 \\
\hline Average & $2 "$ & 180 & $83 \%$ & 10.8 & 9.1 & 10.0 & 0.4 & 0.6 \\
\hline \multicolumn{9}{|c|}{ Enclosure 2" hole All Data } \\
\hline $0^{\circ}$ & $2 "$ & all & all & 12.7 & 8.8 & 10.7 & 0.3 & 0.3 \\
\hline $90^{\circ}$ & $2^{\prime \prime}$ & all & all & 8.0 & 7.8 & 7.9 & 0.4 & 0.5 \\
\hline $180^{\circ}$ & $2 "$ & all & all & 4.8 & 5.6 & 5.2 & 0.4 & 0.3 \\
\hline $270^{\circ}$ & $2^{\prime \prime}$ & all & all & 10.6 & 7.1 & 8.8 & 0.5 & 0.7 \\
\hline Average & $2^{\prime \prime}$ & all & all & 9.0 & 7.3 & 8.2 & 0.4 & 0.4 \\
\hline
\end{tabular}


Table 13 shows the IL of the noise enclosure with a 2" hole for all treatment conditions. The IL values ranged from 3.0 dBA to $15.5 \mathrm{dBA}$, depending on the Distance, Microphone Location and Insulation. Figure 12 shows the IL of the noise enclosure across two levels of Insulation (0\% and $83 \%)$ for conditions where the Hole Diameter was $2^{\prime \prime}$. Note that the enclosure was rotated $180^{\circ}$ for some tests so that the speaker no longer faced the hole. With all these conditions considered, the Microphones Locations of $0^{\circ}$ and $270^{\circ}$ had differences in IL between 4 and 8 feet of about $4 \mathrm{dBA}$. Microphone Locations of $90^{\circ}$ and $180^{\circ}$ had differences at the two Distances of less than $1 \mathrm{dBA}$. At Microphone Locations $=0^{\circ}$ and $270^{\circ}$ the variations were 3.9 and $3.6 \mathrm{dBA}$ respectively. To an extent variations could be expected at Distances $=4$ and 8 feet due to 4 feet being in the near field.

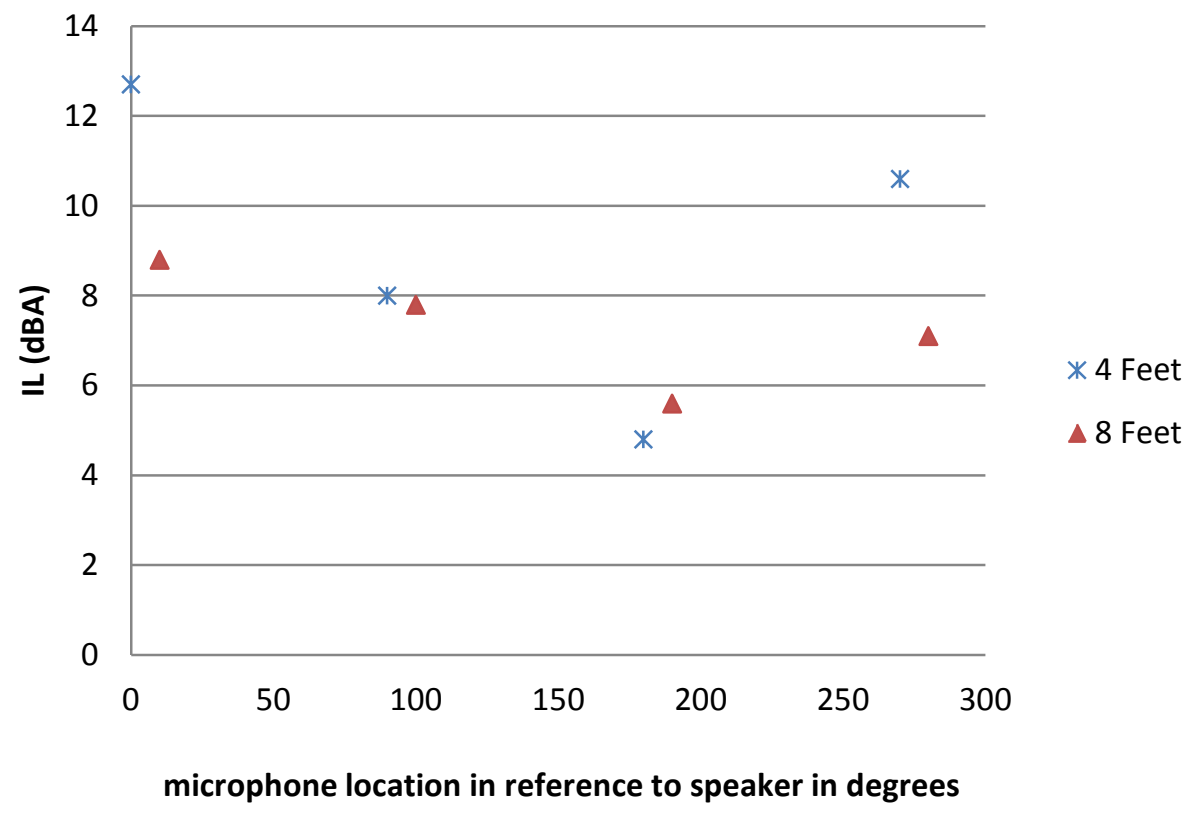

Figure 11. Average Insertion Loss of noise enclosure with 2" hole 


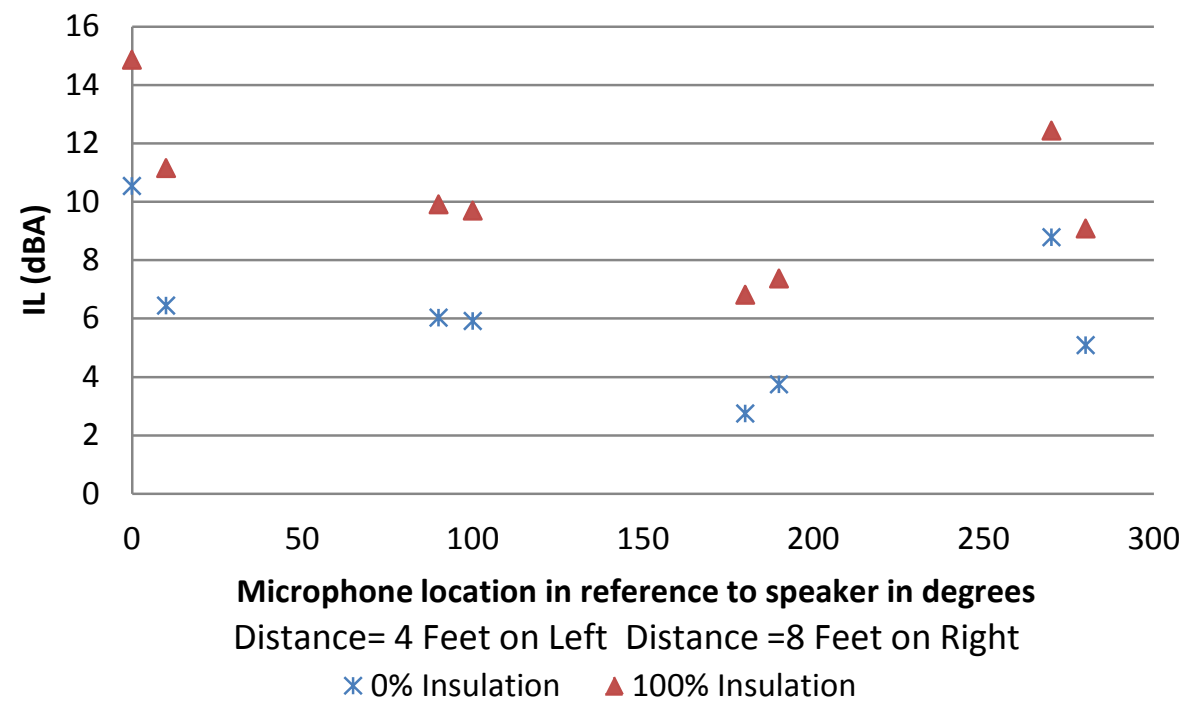

Figure 12. Effect of insulation on IL of enclosure with 2" hole

Figure 12 shows IL values with different levels of Insulation when the noise enclosure had a 2" hole on one side. The IL values increased approximately 4 to $5 \mathrm{dBA}$ in every direction when more insulation was applied to the inside of the enclosure. This matched the results of study 1 that indicated an average increase of $4.1 \mathrm{dBA}$ when $83 \%$ insulation was added to the enclosure. 


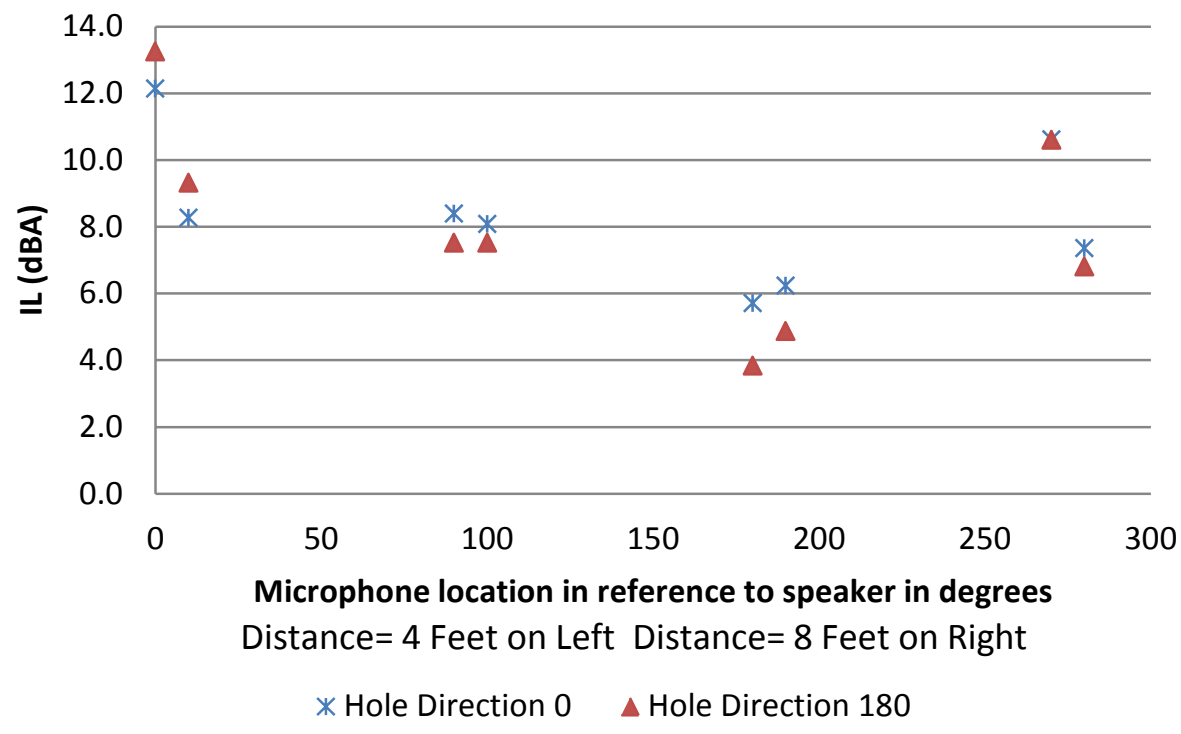

Figure 13. Effect of hole direction on IL of enclosure with 2" hole

Figure 13 shows the effect of whether the speaker faces the hole or the opposite direction when there was a 2 " hole in the enclosure averaged across all levels of insulation $10 \%$ and $83 \%$ ). For Directions $90^{\circ}$ and $270^{\circ}$ there was a minimal effect of hole direction on IL, which was expected because those two sides were adjacent to the side with the hole. There was a $1 \mathrm{dBA}$ decrease at both values of Distance when the hole was facing Directions $=0^{\circ}$. When the hole was facing $180^{\circ}$ there was nearly a $2 \mathrm{dBA}$ decrease in IL values. Thus, as expected IL was affected the most on the side the hole was facing. 
Table 14. Insertion Loss of Noise Enclosure with 4" hole

\begin{tabular}{|c|c|c|c|c|c|c|c|c|}
\hline & & & & Mean & Mean & Mean & StdD & StdD \\
\hline Direction & $\begin{array}{c}\text { Hole } \\
\text { Diameter }\end{array}$ & $\begin{array}{c}\text { Hole } \\
\text { direction }\end{array}$ & Insulation & Dist $=4$ & Dist $=81$ & Avg & Dist=4' & Dist $=81$ \\
\hline \multicolumn{9}{|c|}{ Hole facing $0^{\circ}$} \\
\hline $0^{\circ}$ & $4 "$ & 0 & $0 \%$ & 5.8 & 4.5 & 5.2 & 0.3 & 0.2 \\
\hline $90^{\circ}$ & $4 "$ & 0 & $0 \%$ & 6.6 & 5.1 & 5.9 & 0.2 & 0.0 \\
\hline $180^{\circ}$ & $4 "$ & 0 & $0 \%$ & 2.6 & 5.5 & 4.0 & 0.2 & 0.2 \\
\hline $270^{\circ}$ & $4 "$ & 0 & $0 \%$ & 6.6 & 5.4 & 6.0 & 0.1 & 0.1 \\
\hline Average & $4 "$ & 0 & $0 \%$ & 5.4 & 5.1 & 5.3 & 0.2 & 0.1 \\
\hline \multicolumn{9}{|c|}{ Hole facing $180^{\circ}$} \\
\hline $0^{\circ}$ & $4 "$ & 180 & $0 \%$ & 8.7 & 7.4 & 8.0 & 0.3 & 0.3 \\
\hline $90^{\circ}$ & $4 "$ & 180 & $0 \%$ & 6.3 & 5.6 & 5.9 & 0.1 & 0.1 \\
\hline $180^{\circ}$ & $4 "$ & 180 & $0 \%$ & 0.4 & 3.4 & 1.9 & 0.2 & 0.2 \\
\hline $270^{\circ}$ & $4 "$ & 180 & $0 \%$ & 8.1 & 6.0 & 7.0 & 0.2 & 0.1 \\
\hline Average & $4 "$ & 180 & $0 \%$ & 5.9 & 5.6 & 5.7 & 0.2 & 0.2 \\
\hline \multicolumn{9}{|c|}{ Hole facing $0^{\circ}$} \\
\hline $0^{\circ}$ & $4 "$ & 0 & $83 \%$ & 9.6 & 8.9 & 9.2 & 0.2 & 0.3 \\
\hline $90^{\circ}$ & $4 "$ & 0 & $83 \%$ & 9.9 & 8.8 & 9.4 & 0.5 & 0.4 \\
\hline $180^{\circ}$ & $4 "$ & 0 & $83 \%$ & 7.7 & 9.2 & 8.5 & 0.4 & 0.3 \\
\hline $270^{\circ}$ & $4 "$ & 0 & $83 \%$ & 10.0 & 9.0 & 9.5 & 0.4 & 0.7 \\
\hline Average & $4 "$ & 0 & $83 \%$ & 9.3 & 9.0 & 9.2 & 0.4 & 0.4 \\
\hline \multicolumn{9}{|c|}{ Hole facing $180^{\circ}$} \\
\hline $0^{\circ}$ & $4 "$ & 180 & $83 \%$ & 12.8 & 11.6 & 12.2 & 0.6 & 0.4 \\
\hline $90^{\circ}$ & $4 "$ & 180 & $83 \%$ & 9.4 & 8.1 & 8.8 & 0.8 & 1.1 \\
\hline $180^{\circ}$ & $4 "$ & 180 & $83 \%$ & 4.1 & 7.2 & 5.7 & 0.5 & 0.6 \\
\hline $270^{\circ}$ & $4 "$ & 180 & $83 \%$ & 10.1 & 8.1 & 9.1 & 0.9 & 1.3 \\
\hline Average & $4 "$ & 180 & $83 \%$ & 9.1 & 8.8 & 8.9 & 0.7 & 0.8 \\
\hline \multicolumn{9}{|c|}{ All 4" Enclosure Data } \\
\hline $0^{\circ}$ & $4 "$ & all & all & 9.2 & 8.1 & 8.6 & 0.3 & 0.3 \\
\hline $90^{\circ}$ & $4 "$ & all & all & 8.1 & 6.9 & 7.5 & 0.4 & 0.4 \\
\hline $180^{\circ}$ & $4 "$ & all & all & 3.7 & 6.3 & 5.0 & 0.3 & 0.3 \\
\hline $270^{\circ}$ & $4 "$ & all & all & 8.7 & 7.1 & 7.9 & 0.4 & 0.6 \\
\hline Average & $4 "$ & all & all & 7.4 & 7.1 & 7.3 & 0.4 & 0.4 \\
\hline
\end{tabular}


Table 14 shows the average IL values when the enclosure had a 4" hole. The individual location IL values ranged from $0.4 \mathrm{dBA}$ to $12.8 \mathrm{dBA}$. In all four directions there was a $0.3 \mathrm{dBA}$ difference between the IL values at 4 and 8 feet. This agreed with the results of Study One that distance did not affect IL values. Figure 14 shows the IL of the noise enclosure across both levels of Insulation ( $0 \%$ and $83 \%$ ) for a $4^{\prime \prime}$ hole diameter to cases where the hole direction was either $0^{\circ}$ and $180^{\circ}$. In all directions at a distance of 8 feet the variation was less than $2.5 \mathrm{dBA}$. At a distance of 4 feet all of the IL values were within $1.5 \mathrm{dBA}$ except Microphone Location $=180$ which was 5 dBA less.

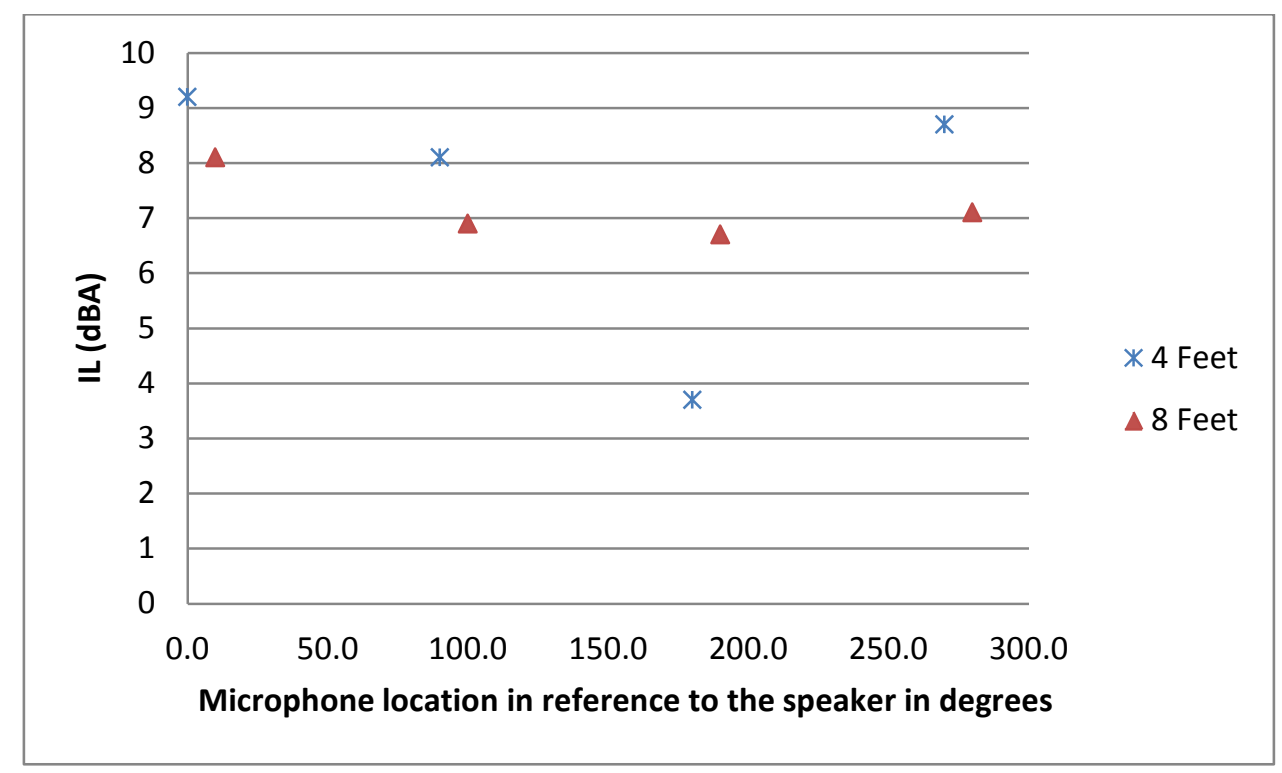

Figure 14. Average IL of enclosure with 4" hole 


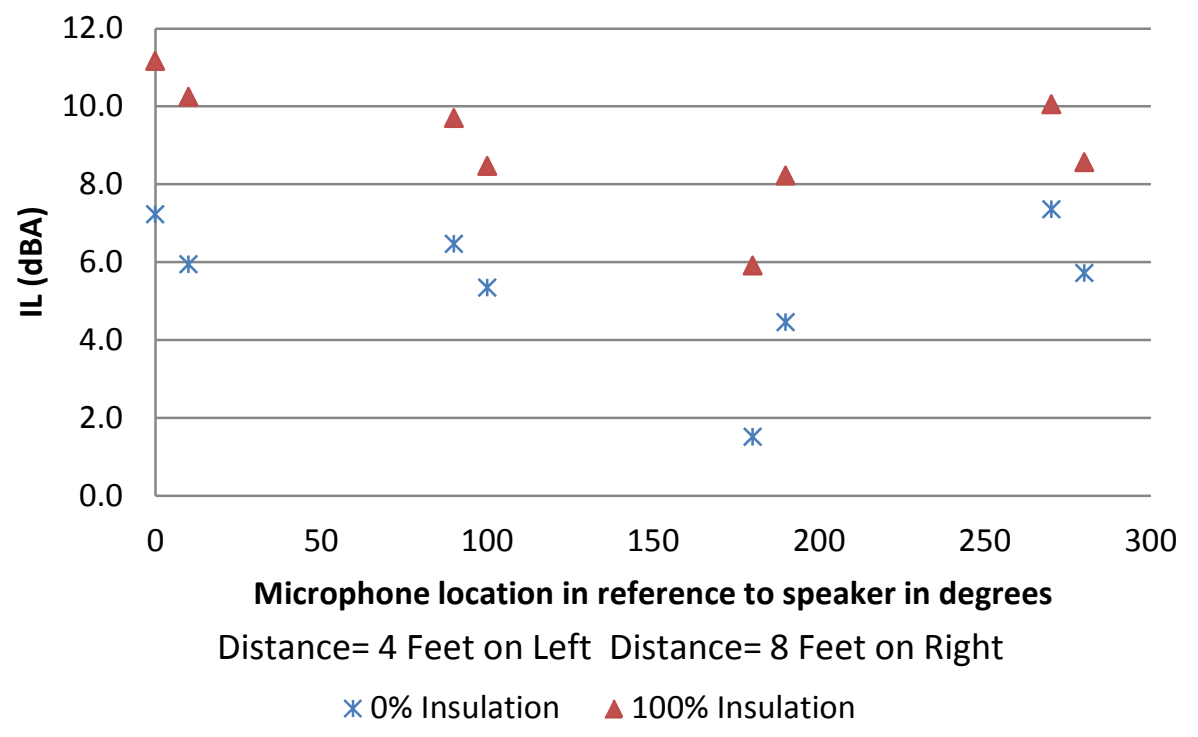

Figure 15. Effect of insulation on IL of enclosure with a 4" hole averaged over all hole directions

Figure 15 shows the effect of insulation on the IL of the enclosure with a 4" hole when averaged over all levels of hole direction $\left(0^{\circ}\right.$ and $\left.180^{\circ}\right)$. The overall effect of the insulation ranged from 3 to $4 \mathrm{dBA}$ at each individual Microphone Location, which is slightly lower than the $4.1 \mathrm{dBA}$ increase in IL predicted from Study One. These results indicate that as hole size gets larger the effectiveness of insulation may be reduced. 


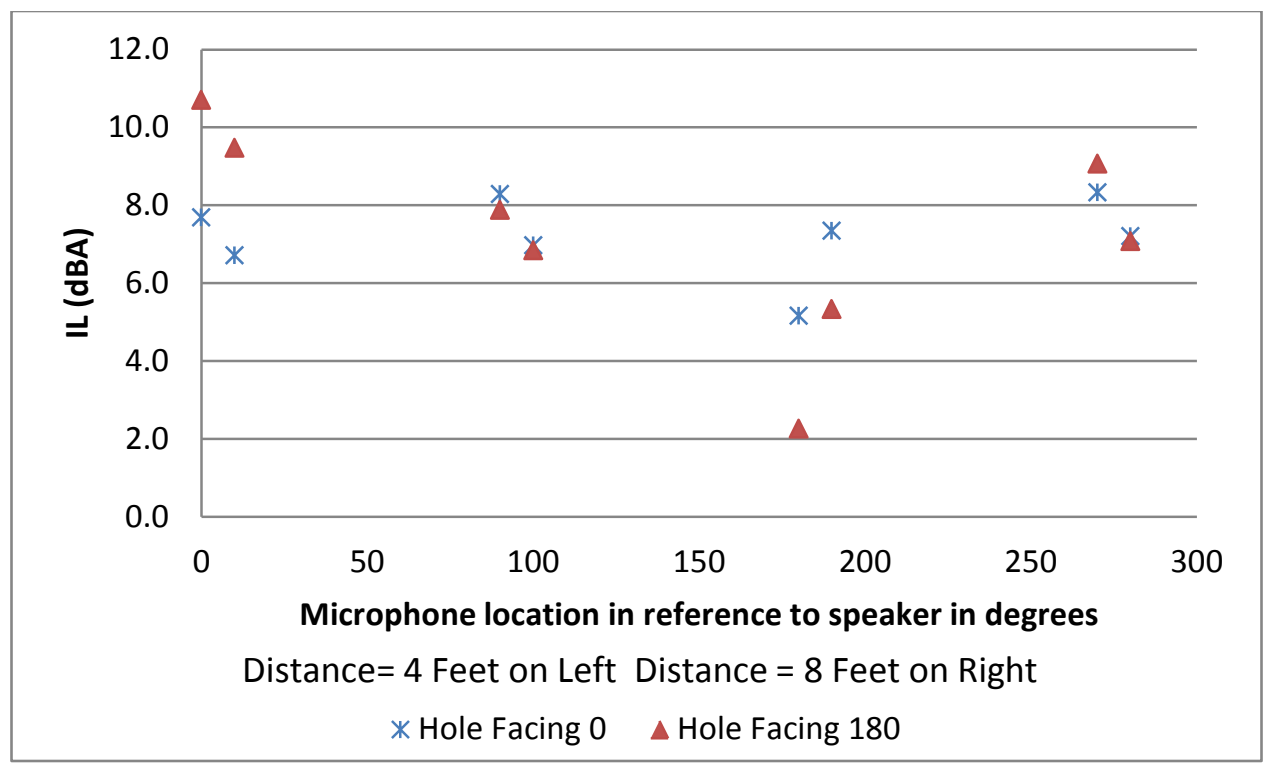

Figure 16. Effect of hole direction on IL of enclosure with 4" hole averaged across all levels of insulation.

Figure 16 shows the effect of whether the speaker faces the hole or the opposite direction when there was a 4 " hole in the enclosure averaged across all levels of insulation ( $0 \%$ and $83 \%$ ). In the directions of $90^{\circ}$ and $270^{\circ}$ there was a minimal effect on IL values due to rotating the enclosure from $0^{\circ}$ to $180^{\circ}$. This was expected because neither the speaker nor the hole is facing these directions. However, there was a 2-4 dBA reduction in IL values on the side the hole was facing. 
Table 15. Effect of Hole Size on Insertion Loss

\begin{tabular}{|c|c|c|c|c|c|c|c|}
\hline \multirow[b]{2}{*}{ Direction } & \multirow[b]{2}{*}{ Insulation } & \multicolumn{2}{|c|}{ Enclosure 0" hole } & \multicolumn{2}{|c|}{ Enclosure 2" hole } & \multicolumn{2}{|c|}{ Enclosure 4" hole } \\
\hline & & $\underline{4 \text { Feet }}$ & $\underline{8 \text { Feet }}$ & $\underline{4 \text { Feet }}$ & $\underline{8 \text { Feet }}$ & $\underline{4 \text { Feet }}$ & $\underline{8 \text { Feet }}$ \\
\hline & & \multicolumn{6}{|c|}{ Hole Facing $0^{\circ}$} \\
\hline 0 & $0 \%$ & 8.3 & 7.1 & 10.1 & 5.9 & 5.8 & 4.5 \\
\hline 90 & $0 \%$ & 6.7 & 6.5 & 6.5 & 6.1 & 6.6 & 5.1 \\
\hline 180 & $0 \%$ & 3.6 & 6.5 & 3.6 & 4.5 & 2.6 & 5.5 \\
\hline 270 & $0 \%$ & 8.6 & 7.7 & 8.8 & 5.2 & 6.6 & 5.4 \\
\hline Avg & $0 \%$ & 6.8 & 7.0 & 7.3 & 5.4 & 5.4 & 5.1 \\
\hline \multirow[t]{2}{*}{ Avg All Dist } & $0 \%$ & \multicolumn{2}{|c|}{6.9} & \multicolumn{2}{|c|}{6.3} & \multicolumn{2}{|c|}{5.3} \\
\hline & & \multicolumn{6}{|c|}{ Hole Facing $180^{\circ}$} \\
\hline 0 & $0 \%$ & 8.3 & 7.1 & 11.0 & 7.0 & 8.7 & 7.4 \\
\hline 90 & $0 \%$ & 6.7 & 6.5 & 5.5 & 5.7 & 6.3 & 5.6 \\
\hline 180 & $0 \%$ & 3.6 & 6.5 & 1.9 & 3.0 & 0.4 & 3.4 \\
\hline 270 & $0 \%$ & 8.6 & 7.7 & 8.8 & 5.0 & 8.1 & 6.0 \\
\hline Avg & $0 \%$ & 6.8 & 7.0 & 6.8 & 5.2 & 5.9 & 5.6 \\
\hline \multirow[t]{2}{*}{ Avg All Dist } & $0 \%$ & \multicolumn{2}{|c|}{6.9} & \multicolumn{2}{|c|}{6.0} & \multicolumn{2}{|c|}{5.7} \\
\hline & & \multicolumn{6}{|c|}{ Hole Facing $0^{\circ}$} \\
\hline 0 & $83 \%$ & 13.2 & 12.1 & 14.2 & 10.6 & 9.6 & 8.9 \\
\hline 90 & $83 \%$ & 11.8 & 10.6 & 10.3 & 10.1 & 9.9 & 8.8 \\
\hline 180 & $83 \%$ & 7.1 & 9.7 & 7.8 & 8.0 & 7.7 & 9.2 \\
\hline 270 & $83 \%$ & 12.0 & 11.4 & 12.4 & 9.5 & 10.0 & 9.0 \\
\hline Avg & $83 \%$ & 11.0 & 11.0 & 11.2 & 9.6 & 9.3 & 9.0 \\
\hline \multirow[t]{2}{*}{ Avg All Dist } & $83 \%$ & \multicolumn{2}{|c|}{11.0} & \multicolumn{2}{|c|}{10.4} & \multicolumn{2}{|c|}{9.2} \\
\hline & & \multicolumn{6}{|c|}{ Hole Facing $180^{\circ}$} \\
\hline 0 & $83 \%$ & 13.2 & 12.1 & 15.5 & 11.6 & 12.8 & 11.6 \\
\hline 90 & $83 \%$ & 11.8 & 10.6 & 9.5 & 9.3 & 9.4 & 8.1 \\
\hline 180 & $83 \%$ & 7.1 & 9.7 & 5.8 & 6.8 & 4.1 & 7.2 \\
\hline 270 & $83 \%$ & 12.0 & 11.4 & 12.4 & 8.7 & 10.1 & 8.1 \\
\hline Avg & $83 \%$ & 11.0 & 11.0 & 10.8 & 9.1 & 9.1 & 8.8 \\
\hline Avg All Dist & $83 \%$ & \multicolumn{2}{|c|}{11.0} & \multicolumn{2}{|c|}{10.0} & \multicolumn{2}{|c|}{8.9} \\
\hline
\end{tabular}

Table 15 shows the effect of hole size on IL of the noise enclosure for all 3 levels of hole $\left(0^{\prime \prime}, 2\right.$ ", and 4 "). Increasing hole size reduced the overall IL of the enclosure but had a much more significant effect on the side of the enclosure that had the hole. The average effect of adding a 2 "hole to the enclosure was $0.8 \mathrm{dBA}$. When a 4 " hole replaced the 2 " hole the average reduction across all microphones was $1.7 \mathrm{dBA}$. As expected the effectiveness of the enclosure decreased with hole size. 


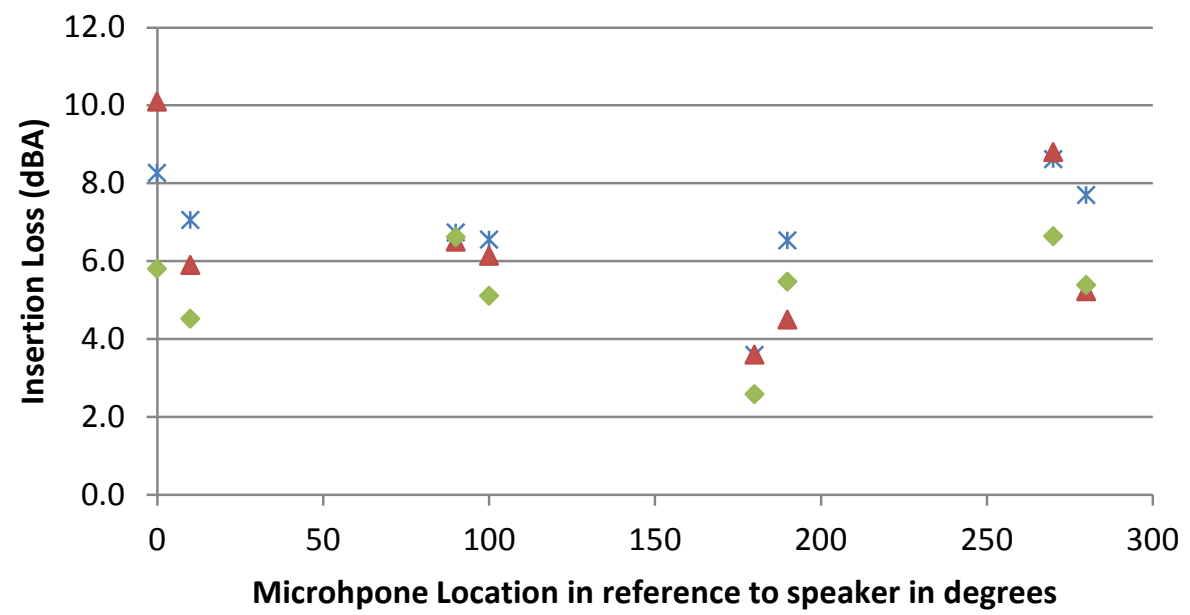

Distance $=4$ Feet on Left Distance $=8$ Feet on Right

* Enclosure No Hole $\Delta$ Enclosure 2" Hole $\quad$ Enclosure 4" Hole

Figure 17. Effects of all sizes of hole on IL when there was $0 \%$ insulation And the hole facing $0^{\circ}$

Figure 17 shows the effects of all hole sizes on the enclosure IL when there was $0 \%$ insulation and the speaker was facing the side with the hole. Prior to the study it was expected that as Hole Diamter was increased that IL would decrease on the side facing the hole. For this data it was true at Distance $=8$ feet but at Distance $=4$ feet it was not true. There are two plausible explanations for this result. The first is that the Distance of 4 feet is within the near field where sound levels are difficult to predict. The second is that the 2 " hole was too small to have a substantial effect on the IL values obtained anywhere other than in line with the hole. 


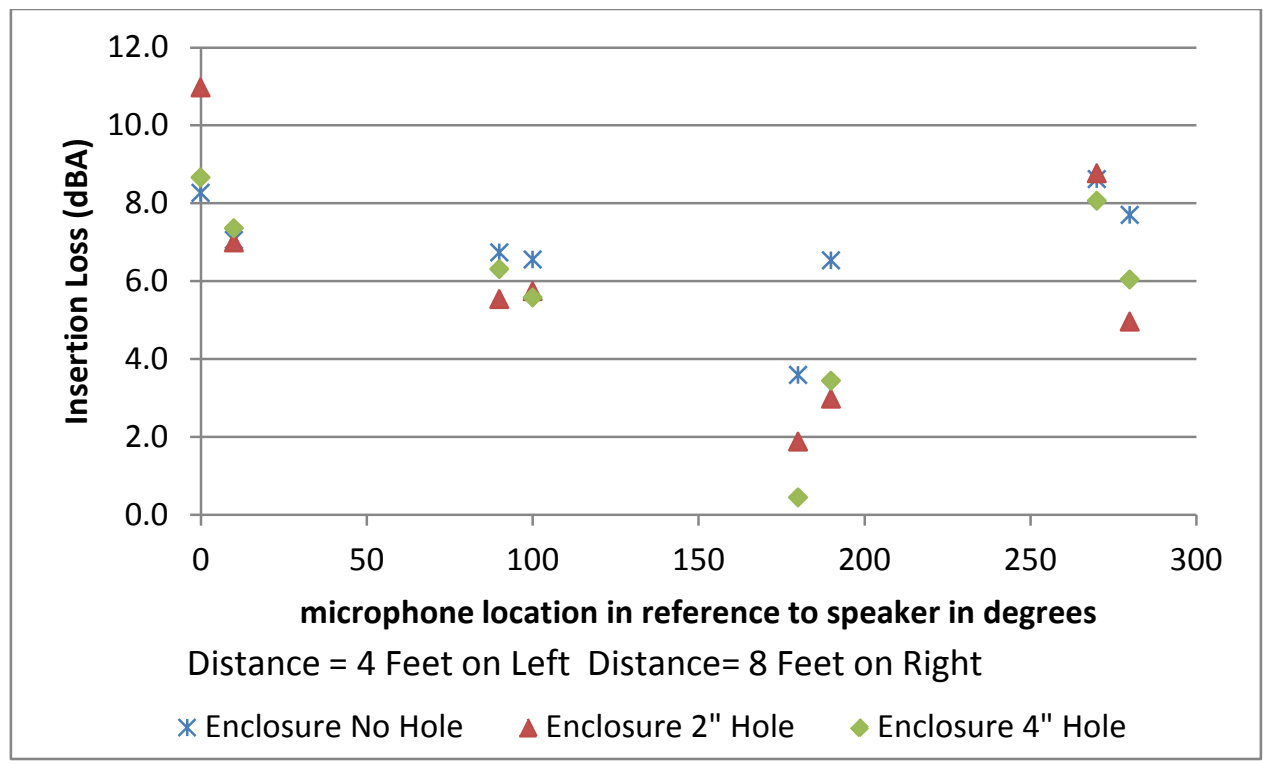

Figure 18. Effects of all sizes of hole on IL when there was $0 \%$ insulation And hole facing $180^{\circ}$

Figure 18 shows the effects of all hole sizes on the enclosures IL when there was $0 \%$ insulation and the speaker was facing away from the hole. Like predicted the lowest IL values were in the Microphone Location $=180^{\circ}$. At Distance $=4$ feet IL values were reduced to $0.4 \mathrm{dBA}$ when their was a $4^{\prime \prime}$ hole. For the direction of $0^{\circ}$ at a distance of 8 feet all of the IL values were within 0.4 $\mathrm{dBA}$ of one another. This shows that the side that is opposite the hole was not affected by the release of noise through the hole. 


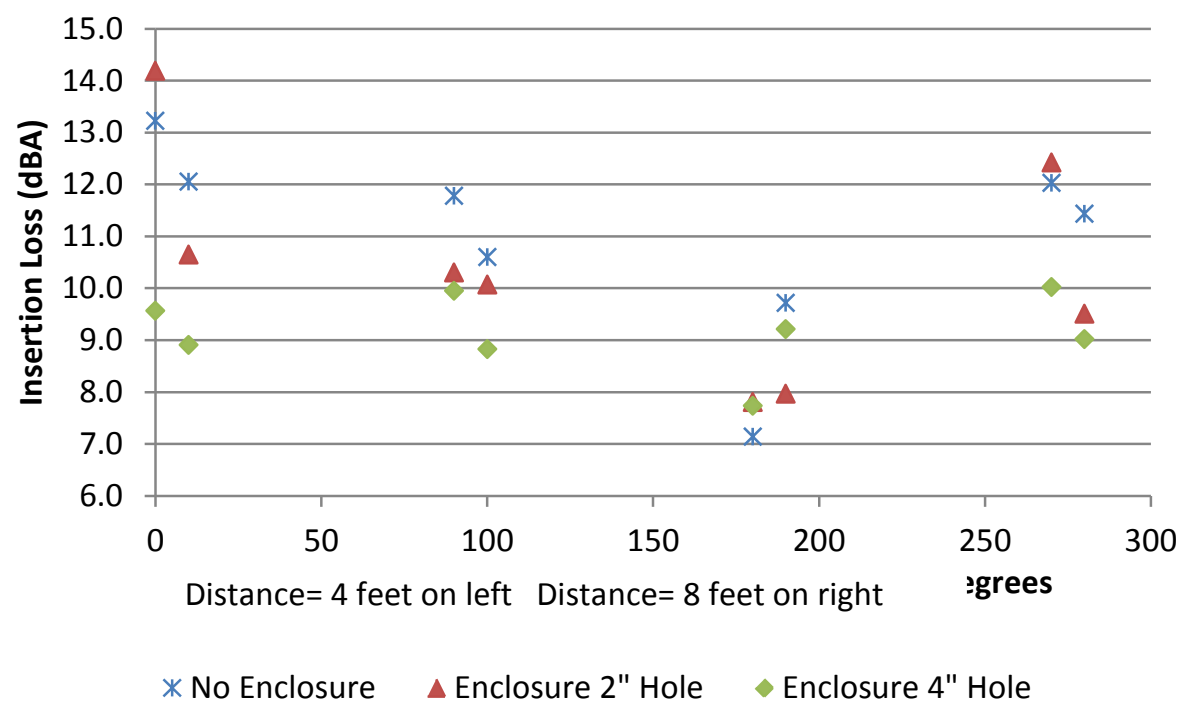

Figure 19. Insertion Loss of enclosure with $83 \%$ insulation and hole facing $0^{\circ}$

Figure 19 shows the effects of all hole sizes ( 0 ", 2 ", and 4") on the enclosures IL when there was $83 \%$ insulation and the speaker and hole were facing $0^{\circ}$. Much like figure 17 the IL values were effected the most in the Microphone Location $=0^{\circ}$. 


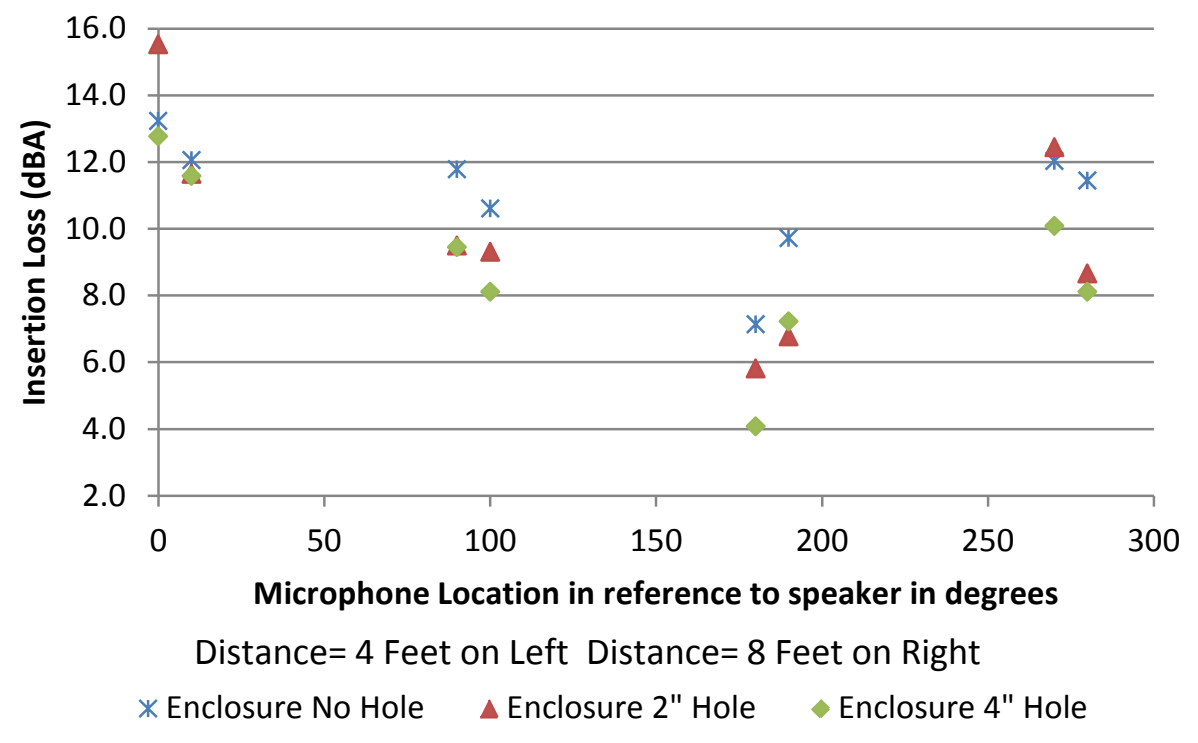

Figure 20. Insertion Loss of enclosure with $83 \%$ insulation and hole facing $180^{\circ}$

Figure 20 shows the effects of all hole sizes ( $0^{\prime \prime}, 2$ ", and 4 ") on the enclosures IL when there was $100 \%$ insulation and the speaker was facing $180^{\circ}$. Much like figure 18 the IL values were reduced the most at Microphone Location $=180^{\circ}$. Although there was $83 \%$ Insulation the IL values were reduced to $4 \mathrm{dBA}$ at Distance $=4$ Feet. At Distance $=8$ Feet the 2 " and 4 " IL values were very similar both around $7 \mathrm{dBA}$. 
Table 16. Effect of Hole Direction on Insertion Loss

\begin{tabular}{|c|c|c|c|c|c|c|}
\hline \multirow[b]{2}{*}{ Direction } & \multirow[b]{2}{*}{ Insulation } & \multicolumn{2}{|c|}{$\begin{array}{c}\text { Enclosure 2" } \\
\text { hole }\end{array}$} & \multicolumn{2}{|c|}{$\begin{array}{c}\text { Enclosure 4" } \\
\text { hole }\end{array}$} & \multirow[t]{2}{*}{$\begin{array}{c}\text { Avg 2" and } \\
4 " \text { hole }\end{array}$} \\
\hline & & 4 Feet & $\underset{8}{\underline{8}}$ & 4 Feet & $\underline{8 \text { Feet }}$ & \\
\hline & \multicolumn{6}{|c|}{ Hole Facing $0^{\circ}$} \\
\hline $0^{\circ}$ & $0 \%$ & 10.1 & 5.9 & 5.8 & 4.5 & 6.6 \\
\hline $90^{\circ}$ & $0 \%$ & 6.5 & 6.1 & 6.6 & 5.1 & 6.1 \\
\hline $180^{\circ}$ & $0 \%$ & 3.6 & 4.5 & 2.6 & 5.5 & 4.0 \\
\hline $270^{\circ}$ & $0 \%$ & 8.8 & 5.2 & 6.6 & 5.4 & 6.5 \\
\hline Avg & $0 \%$ & 7.3 & 5.4 & 5.4 & 5.1 & 5.8 \\
\hline \multirow[t]{2}{*}{ Avg All Dist } & $0 \%$ & \multicolumn{2}{|c|}{6.3} & \multicolumn{2}{|c|}{5.3} & 5.8 \\
\hline & & \multicolumn{5}{|c|}{ Hole Facing $180^{\circ}$} \\
\hline $0^{\circ}$ & $0 \%$ & 11.0 & 7.0 & 8.7 & 7.4 & 8.5 \\
\hline $90^{\circ}$ & $0 \%$ & 5.5 & 5.7 & 6.3 & 5.6 & 5.8 \\
\hline $180^{\circ}$ & $0 \%$ & 1.9 & 3.0 & 0.4 & 3.4 & 2.2 \\
\hline $270^{\circ}$ & $0 \%$ & 8.8 & 5.0 & 8.1 & 6.0 & 7.0 \\
\hline Avg & $0 \%$ & 6.8 & 5.2 & 5.9 & 5.6 & 5.9 \\
\hline \multirow[t]{2}{*}{ Avg All Dist } & $0 \%$ & \multicolumn{2}{|c|}{6.0} & \multicolumn{2}{|c|}{5.7} & 5.9 \\
\hline & & \multicolumn{5}{|c|}{ Hole Facing $0^{\circ}$} \\
\hline $0^{\circ}$ & $83 \%$ & 14.2 & 10.6 & 9.6 & 8.9 & 10.8 \\
\hline $90^{\circ}$ & $83 \%$ & 10.3 & 10.1 & 9.9 & 8.8 & 9.8 \\
\hline $180^{\circ}$ & $83 \%$ & 7.8 & 8.0 & 7.7 & 9.2 & 8.2 \\
\hline $270^{\circ}$ & $83 \%$ & 12.4 & 9.5 & 10.0 & 9.0 & 10.2 \\
\hline Avg & $83 \%$ & 11.2 & 9.6 & 9.3 & 9.0 & 9.8 \\
\hline \multirow[t]{2}{*}{ Avg All Dist } & $83 \%$ & \multicolumn{2}{|c|}{10.4} & \multicolumn{2}{|c|}{9.2} & 9.8 \\
\hline & & \multicolumn{5}{|c|}{ Hole Facing $180^{\circ}$} \\
\hline $0^{\circ}$ & $83 \%$ & 15.5 & 11.6 & 12.8 & 11.6 & 12.9 \\
\hline $90^{\circ}$ & $83 \%$ & 9.5 & 9.3 & 9.4 & 8.1 & 9.1 \\
\hline $180^{\circ}$ & $83 \%$ & 5.8 & 6.8 & 4.1 & 7.2 & 6.0 \\
\hline $270^{\circ}$ & $83 \%$ & 12.4 & 8.7 & 10.1 & 8.1 & 9.8 \\
\hline Avg & $83 \%$ & 10.8 & 9.1 & 9.1 & 8.8 & 9.4 \\
\hline Avg All Dist & $83 \%$ & \multicolumn{2}{|c|}{10.0} & \multicolumn{2}{|c|}{8.9} & 9.4 \\
\hline
\end{tabular}

Table 16 shows the effect of hole direction on the IL of the noise enclosure. The hole direction had a very minimal effect on the IL of the enclosure as a whole. With $0 \%$ acoustical insulation added the overall average IL was $5.8 \mathrm{dBA}$ with the hole facing $0^{\circ}$ and $5.9 \mathrm{dBA}$ with the hole facing $180^{\circ}$. With Insulation $=83 \%$ the overall average IL of the enclosure was $9.8 \mathrm{dBA}$ when the hole was facing $0^{\circ}$ and $9.4 \mathrm{dBA}$ when the hole was facing $180^{\circ}$. Although there was relatively 
little effect on the IL of the entire enclosure, individual locations were effected significantly by hole direction.

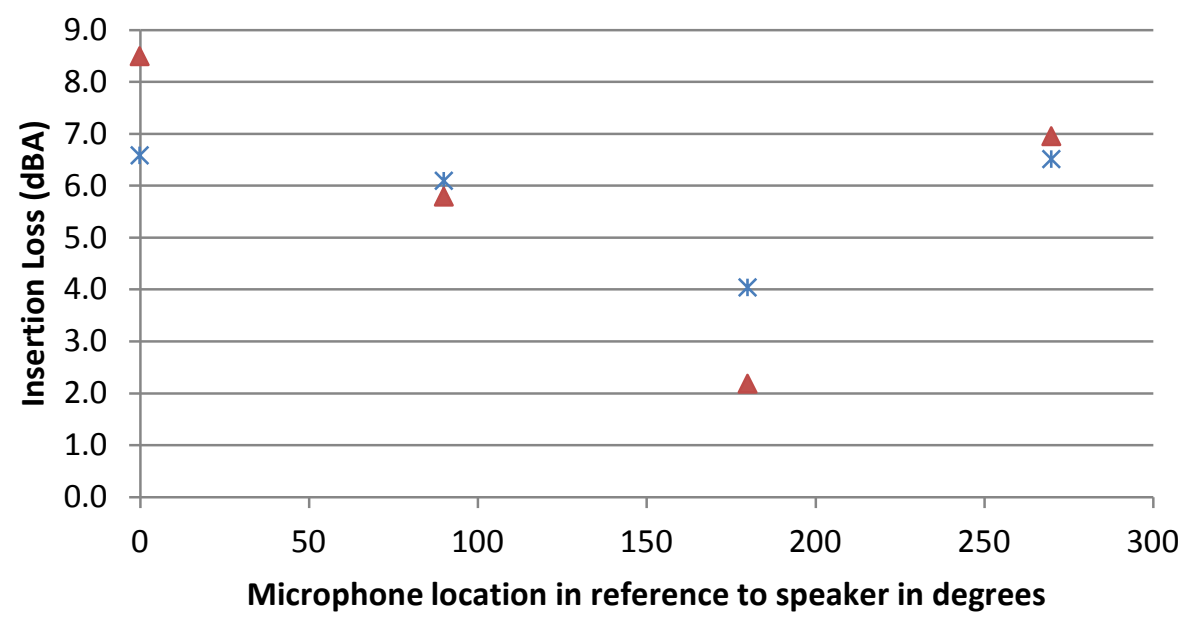

* Enclosure Hole Facing $0 \Delta$ Enclosure Hole Facing 180

Figure 21. Effect of Hole Direction on Insertion Loss across all levels of hole and $0 \%$ insulation

Figure 21 shows the effect of hole direction on the IL of the enclosure when all levels of hole size ( 2 " and 4") are averaged, all distances ( 4 and 8 feet) are averaged and $0 \%$ insulation was used. As expected, the IL levels for Directions of $90^{\circ}$ and $270^{\circ}$ varied by less than $1 \mathrm{dBA}$. The Directions of $0^{\circ}$ and $180^{\circ}$ saw approximately a $2 \mathrm{dBA}$ average decrease in IL when the hole was facing that side. 


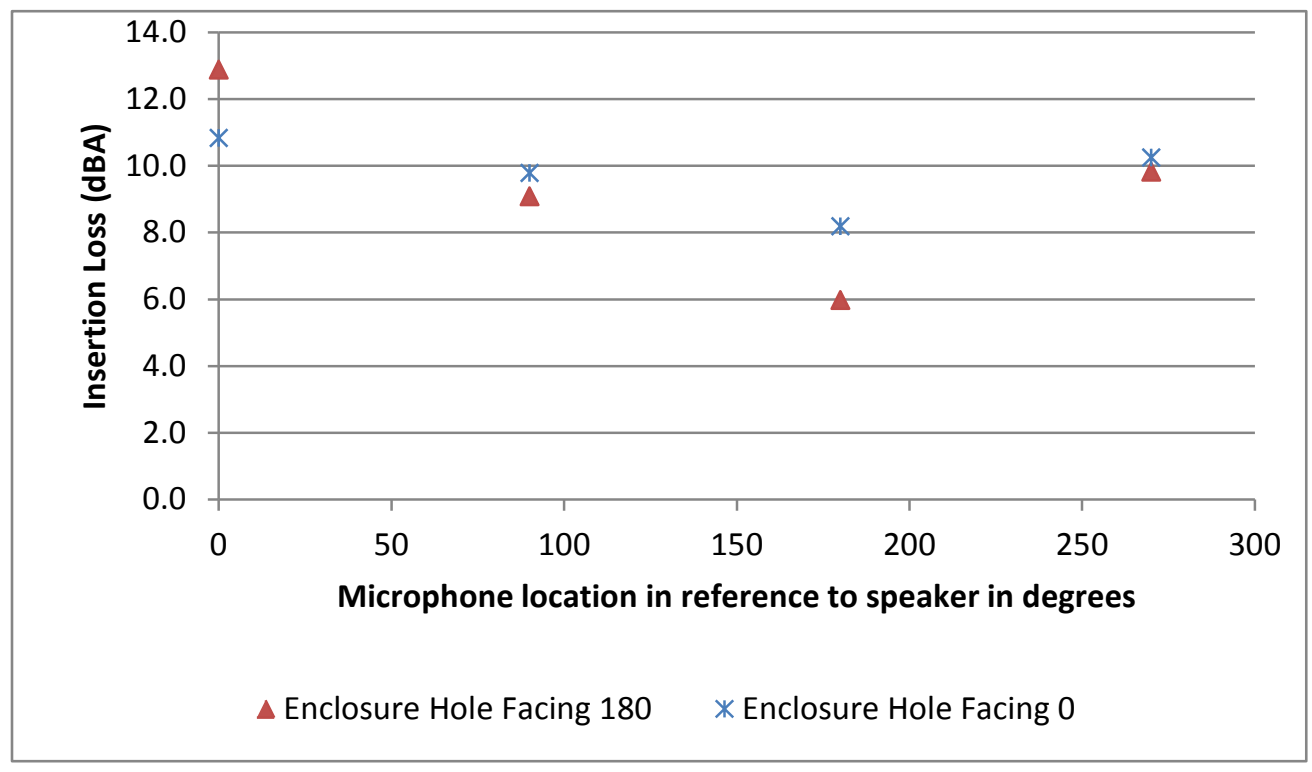

Figure 22. Effect of Hole Direction on Insertion Loss across all levels of hole and $83 \%$ Insulation

Figure 22 shows the effect of hole direction on the IL of the enclosure when all levels of hole size (2" and 4") are averaged, all Distances (4 and 8 feet) are averaged and $83 \%$ insulation was used. As expected, the sides that were adjacent to the hole $\left(90^{\circ}\right.$ and $\left.270^{\circ}\right)$ were within $1.0 \mathrm{dBA}$ of one another. The directions of $0^{\circ}$ and $180^{\circ}$ saw approximately a $2 \mathrm{dBA}$ average decrease in IL when the hole was facing that Microphone Location. 
Table 17. ANOVA Statistics For Study Two

\begin{tabular}{lccccr}
\hline \multicolumn{1}{c}{ Source } & $\begin{array}{c}\text { Degrees } \\
\text { of } \\
\text { Freedom }\end{array}$ & $\begin{array}{c}\text { Sums of } \\
\text { Squares }\end{array}$ & $\begin{array}{c}\text { Mean } \\
\text { Square }\end{array}$ & F-ratio & Probability \\
\hline Constant & 1 & 15532 & 15532 & 6296 & ? 0.0001 \\
Hole Diameter & 1 & 24 & 23 & 10 & 0.0021 \\
Insulation & 1 & 1039 & 1038 & 421 & ? 0.0001 \\
Distance & 1 & 33 & 33 & 13 & 0.0003 \\
Hole Direction & 1 & 2 & 1 & 1 & 0.4104 \\
Mic Location & 3 & 862 & 287 & 116 & ? 0.0001 \\
Distance*Mic Location & 3 & 153 & 51 & 21 & ? 0.0001 \\
Insulation*Mic Location & 3 & 43 & 14 & 6 & 0.0007 \\
Hole Direction* Mic & 3 & 123 & 41 & 17 & ? 0.0001 \\
Location & 1 & 61 & 61 & 25 & ? 0.0001 \\
Hole Diameter* Distance & 236 & 583 & 2 & & \\
Error & 253 & 2903.19 & & & \\
Total & & & & &
\end{tabular}

\section{Statistical Analyses}

ANOVA for Study Two shows that Hole Diameter, Insulation, Distance, and Microphone Location were all significant, while Hole Direction was not. As in Study One, the two individual variables that had the largest effect on IL were Insulation and Microphone Location. They accounted for $36 \%$ and $30 \%$ of the total sum of squares, respectively.

When interactive effects of Hole Direction and Microphone Location were added the model, Hole Direction became significant $(p<0.1 \%)$ The interactive effect of Hole Diameter and Distance was also significant $(p<0.1 \%)$. 
Table 18. Scheffe Post Hoc of the Interaction Between Hole Direction and Microphone Location

\begin{tabular}{|c|c|c|c|c|}
\hline $\begin{array}{l}\text { Mic Loc ,Hole Dir- } \\
\text { Mic Loc, Hole Dir }\end{array}$ & $\begin{array}{c}\text { IL } \\
\text { Difference }\end{array}$ & Std. err. & Probability & Significance \\
\hline $0,180-0,0$ & 1.87685 & 0.3989 & $9.56 \mathrm{E}-05$ & $*$ \\
\hline $90,0-0,0$ & -1.37143 & 0.3959 & 0.00837906 & $*$ \\
\hline $90,0-0,180$ & -3.24828 & 0.3959 & 8.15E-13 & $*$ \\
\hline $90,180-0,0$ & -1.87315 & 0.3959 & 8.58E-05 & $*$ \\
\hline $90,180-0,180$ & -3.75 & 0.3959 & $2.22 \mathrm{E}-16$ & $*$ \\
\hline $90,180-90,0$ & -0.501719 & 0.3926 & 0.652485 & \\
\hline $180,0-0,0$ & -3.19759 & 0.3959 & $1.82 \mathrm{E}-12$ & $*$ \\
\hline $180,0-0,180$ & -5.07444 & 0.3959 & 0 & $* *$ \\
\hline $180,0-90,0$ & -1.82616 & 0.3926 & 1.19E-04 & $*$ \\
\hline $180,0-90,180$ & -1.32444 & 0.3926 & 0.0110157 & $*$ \\
\hline $180,180-0,0$ & -5.23637 & 0.3959 & 0 & $* *$ \\
\hline $180,180-0,180$ & -7.11322 & 0.3959 & 0 & $* *$ \\
\hline $180,180-90,0$ & -3.86494 & 0.3926 & 0 & $*$ \\
\hline $180,180-90,180$ & -3.36322 & 0.3926 & 8.14E-14 & $*$ \\
\hline $180,180-180,0$ & -2.03878 & 0.3926 & 1.17E-05 & $*$ \\
\hline $270,0-0,0$ & -0.937474 & 0.3959 & 0.135548 & \\
\hline $270,0-0,180$ & -2.81433 & 0.3959 & $6.03 E-10$ & $*$ \\
\hline $270,0-90,0$ & 0.433955 & 0.3926 & 0.747998 & \\
\hline $270,0-90,180$ & 0.935674 & 0.3926 & 0.131453 & \\
\hline $270,0-180,0$ & 2.26011 & 0.3926 & $8.22 \mathrm{E}-07$ & $*$ \\
\hline $270,0-180,180$ & 4.2989 & 0.3926 & 0 & $*$ \\
\hline $270,180-0,0$ & -0.923982 & 0.3959 & 0.145033 & \\
\hline $270,180-0,180$ & -2.80083 & 0.3959 & 7.33E-10 & $*$ \\
\hline $270,180-90,0$ & 0.447447 & 0.3926 & 0.729661 & \\
\hline $270,180-90,180$ & 0.949166 & 0.3926 & 0.122576 & \\
\hline $270,180-180,0$ & 2.27361 & 0.3926 & $6.94 \mathrm{E}-07$ & $*$ \\
\hline $270,180-180,180$ & 4.31239 & 0.3926 & 0 & $*$ \\
\hline $270,180-270,0$ & 0.0134919 & 0.3926 & 0.999989 & \\
\hline
\end{tabular}

${ }^{*}$ Results are statistically significant $(p<.05) \quad * * p=0$ and IL Difference greater than $5 \mathrm{dBA}$

Table 18 shows the interactive effect between Hole Direction and Microphone Location. The individual test conditions that had the largest difference in IL values was when the Microphone Location was $180^{\circ}$ and the Hole Direction was $180^{\circ}$ compared to the IL values when the Microphone Location was $0^{\circ}$ and the Hole Direction was $180^{\circ}$. This was expected because the 
test is comparing the Microphone Locations that are on the opposite side as hole to Microphone Locations that are on the same side as the hole.

Table 19. Scheffe Post Hoc on the Interactive Effect of Distance and Hole Diameter

\begin{tabular}{cccc}
\hline $\begin{array}{c}\text { Distance(Ft), Hole dia(In)- } \\
\text { Distance(Ft) , Hole dia(In) }\end{array}$ & $\begin{array}{c}\text { Difference } \\
\text { in IL (dBA) }\end{array}$ & $\begin{array}{l}\text { std. } \\
\text { err. }\end{array}$ & Probability \\
\hline $4,4-4,2$ & -1.6 & 0.30 & $3.08 \mathrm{E}-08^{*}$ \\
$8,2-4,2$ & -1.7 & 0.30 & $3.78 \mathrm{E}-09^{*}$ \\
$8,2-4,4$ & -0.1 & 0.30 & 0.692561 \\
$8,4-4,2$ & -1.3 & 0.30 & $3.14 \mathrm{E}-06^{*}$ \\
$8,4-4,4$ & 0.3 & 0.30 & 0.367506 \\
$8,4-8,2$ & 0.4 & 0.30 & 0.196473 \\
\hline
\end{tabular}

* Results that are statistically significant $(p<0.0001)$

Table 19 shows the interactive effect of distance and Hole Diameter. Of the values that were statistically significant $(p<0.01)$ two of them were comparing different distances that had different hole sizes. Prior to the study, it was expected that Distance would not have an effect on IL and Hole Diameter would. Table 19 confirmed this. It was not expected that having a 2" hole would create would create a difference at 4 and 8 feet but as the tables shows it did. On the day 2" hole data was collected IL values at 4 feet were slightly higher than at 8 feet. This could have been potentially caused by the near field. 


\section{CONCLUSIONS FOR STUDY TWO}

The first major conclusion was that the enclosure was still somewhat effective at reducing noise levels (IL > .4 dBA) at all Microphone Location under all conditions. However, the average enclosure IL values were up to 2.1 dBA lower when there was a 4" hole present. This accounted for $16 \%$ of the overall IL of the enclosure.

The second conclusion from Study Two was that IL of the enclosure decreased as the hole diameter increases. Clearly, to achieve the maximum IL for the noise enclosure holes should be reduced to a minimum.

The final conclusion was that when Insulation was added to the enclosure it was still effective at increasing IL values although there was a hole. However, there was a slight drop in IL values when the hole size was increased to 4", suggesting that as hole size began to get larger the Insulation would become less effective.

\section{Overall Conclusions}

This simple noise enclosure constructed of plywood is modestly effective at reducing the overall sound pressure level around the sound source. The enclosure without insulation provided a 6.9 dBA average Insertion loss (IL) for the sound source. When the insulation was increased to $50 \%$ and $83 \%$ percent the IL values were increased to 10.2 and $11.0 \mathrm{dBA}$, respectively.

When holes were added to the enclosure the IL values were reduced by a minimum average of $0.6 \mathrm{dBA}$ when there was a 2 " hole and a maximum of $1.8 \mathrm{dBA}$ when there was a 4 " hole.

Finally, Microphone Location (i.e., which side of the enclosure the measurements were taken] was important to the level of IL, especially when there was a hole in the enclosure. The holes reduced the $\mathrm{IL}$ of the side that they were facing Typically on the side opposite that the holes were facing there was a slight increase of IL. 
These studies suggest that a roughly constructed and installed simple plywood box can be at least modestly effective in reducing noise exposures to those in the vicinity of the source. It is likely that the IL values would have been at least somewhat higher had the enclosure been substantially lower. If the frequency distribution of the source had been dominated by low frequency sound the IL would almost certainly would have been lower. Since both the source and the enclosure rested on the same hard rubber mat, it is likely that there was some direct transmission of vibration to the enclosure, possibly causing the enclosure to produce sound itself. 


\section{ReferenCES}

Berger, E.H., Royster, L.H., Royster, J.D., Driscoll, D.P., \& Layne, M. (Ed.). (2000). The noise manual fifth edition. Fairfax Virginia: AlHA Press.

Blanks, J. (1997). Optimal design of an enclosure for a portable generator. Mechanical Engineering, Virginia Tech, Blacksburg, VA. Retrieved from http://scholar.lib.vt.edu/theses/public/etd-145110201974500/etd.pdf

Buckingham, E. (1924). "Theory and interpretation of experiments on the transmission of sound through partition walls", Sci. Papers Natn. Bur. Standards vol. 20, p.193

CDC/NIOSH. (2001). Work related hearing loss. Retrieved from http://www.cdc.gov/niosh/docs/2001-103/

CDC/NIOSH. (2011, May 10). Noise and hearing loss prevention. Retrieved from http://www.cdc.gov/niosh/topics/noise/stats.html

Enoise Control. (2012). Sound enclosures. Retrieved from http://enoisecontrol.com/soundenclosures.html

Hegde, A. (2005). Effect of opening size on the effectiveness of a noise enclosure on the sides facing the opening. Unpublished manuscript, Industrial Engineering, West Virginia, Morgantown, WV.

IAC acoustics. (2012). Acoustical enclosures. Retrieved from http://www.industrialacoustics.com/uk/industry/acoustic-

Lund, A. (1979). Noise control enclosures for industrial equipment. AlHA Journal, 40(11), 961969.

Ministry of Manpower. (2003). Guidelines for noise control and vibration.

Norton, M, \& Karczub, D. (2003). Fundamentals of noise and vibration analysis for engineers. Cambridge: University Press.

Oldham, D.J. and Hilarby, S.N., (1991). "The Acoustical Performance of Small Close Fitting Enclosures, Part 1; Theoretical Models", Journal of Sound and Vibration, vol. 150 pp. 261- 81

Oldham, D.J. and Hilarby, S.N., (1991). "The Acoustical Performance of Small Close Fitting Enclosures, Part 2; Theoretical Models", Journal of Sound and Vibration, vol. 150 pp. 283-300 


\section{Caveats}

- These tests were performed in a room where there was not a free field. There were possible reflections off of metal pipes located behind some of the microphones.

- Vibration measurements were not taken with an accelerometer to test the sound transmission of the enclosure.

\section{APPENDIX}

\section{Appendix I Calculations listed in Table}

\section{Calculations for $\alpha_{\text {total, }}$ Room Value, and $\mathrm{TL}_{\text {combined }}$}

$\underline{\alpha}_{\text {total }}$

$\alpha_{\text {total }}=\frac{\sum_{1}^{n}\left(s_{1} \alpha_{1+} s_{2} \alpha_{2+\ldots} s_{n} \alpha_{n}\right)}{\sum_{1}^{n}\left(s_{1+} s_{2+\ldots} s_{n}\right)}$

$\alpha_{\text {total }}$ of bare enclosure

$\alpha_{\text {total }}=\frac{\left(.75 \mathrm{~m}^{2} * .75 \mathrm{~m}^{2} * 5\right) * .15}{\left(.75 \mathrm{~m}^{2} * .75 \mathrm{~m}^{2}\right) * 5}$

$\alpha_{\text {total }}=.15$

$\alpha_{\text {total }}$ of enclosure with $50 \%$ acoustical insulation

$\alpha_{\text {total }}=\frac{\left(.75 \mathrm{~m}^{2} * .75 \mathrm{~m}^{2} * 3\right) * .45+\left(.75 \mathrm{~m}^{2} * .75 \mathrm{~m}^{2} * 2\right) * .15}{\left(.75 \mathrm{~m}^{2} * .75 \mathrm{~m}^{2} * 3\right)+\left(.75 \mathrm{~m}^{2} * .75 \mathrm{~m}^{2} * 2\right)}$

$\alpha_{\text {total }}=.33$

$\alpha_{\text {total }}$ of enclosure with $100 \%$ acoustical insulation

$\alpha_{\text {total }}=\frac{\left(.75 \mathrm{~m}^{2} * .75 \mathrm{~m}^{2} * 5\right) * .45}{\left(.75 \mathrm{~m}^{2} * .75 \mathrm{~m}^{2} * 5\right)}$

$\alpha_{\text {total }}=.45$

Room Value 
$R=\frac{S \alpha_{\text {total }}}{1-\alpha_{\text {total }}}$

Room Value of enclosure with $0 \%$ insulation

$R=\frac{\left(.75 m^{2} * .75 m^{2} * 5\right) *(.15)}{(1-.15)}$

$R=.4963 \mathrm{~m}^{2}$

Room Value of enclosure with $50 \%$ insulation

$R=\frac{\left(.75 m^{2} * .75 m^{2} * 5\right) *(.33)}{(1-.33)}$

$R=1.3852 \mathrm{~m}^{2}$

Room Value of enclosure with $100 \%$ insulation

$R=\frac{\left(.75 m^{2} * .75 m^{2} * 5\right) *(.45)}{(1-.45)}$

$R=2.3011 \mathrm{~m}^{2}$

$\underline{T L_{\text {combined }}}$

$T L_{\text {Combined }}=10 \log \frac{\sum_{1}^{n} S_{i}}{\sum_{1}^{n} S_{i}\left(10^{-T L / 10}\right)}$

Enclosure No Hole

$T L_{\text {Combined }}=10 \log \frac{2.8125 \mathrm{~m}^{2}}{2.8125 \mathrm{~m}^{2} *\left(10^{-\frac{25.5}{10}}\right)}$

$T L_{\text {Combined }}=25.5 \mathrm{~dB}$

Enclosure 2" Hole

$T L_{\text {Combined }}=10 \log \frac{2.8125 m^{2}}{2.8105 m^{2} *\left(10^{-\frac{25.5}{10}}\right)+.002 m^{2} *\left(10^{-\frac{0}{10}}\right)}$

$T L_{\text {Combined }}=24.5 \mathrm{~dB}$

Enclosure 4" Hole 


$$
T L_{\text {Combined }}=10 \log \frac{2.8125 \mathrm{~m}^{2}}{2.8045 \mathrm{~m}^{2} *\left(10^{-\frac{25.5}{10}}\right)+.008 \mathrm{~m}^{2} *\left(10^{-\frac{0}{10}}\right)}
$$

$T L_{\text {Combined }}=22.5 \mathrm{~dB}$

\section{Insertion Loss Predictions}

Equation for predicting insertion loss up transmission loss and $\alpha_{\text {total }}$.

$I L=T L_{\text {combined }}+10 \log \left(\alpha_{\text {total }}\right) d B$

Enclosure with 0\% Insulation and No Hole

$I L=25.5+10 \log .15$

$I L=17.3 \mathrm{~dB}$

Enclosure with 50\% Insulation and No Hole

$I L=25.5+10 \log .33$

$I L=20.7 \mathrm{~dB}$

Enclosure with $100 \%$ Insulation and No Hole

$I L=25.5+10 \log .45$

$I L=22.0 \mathrm{~dB}$

Enclosure with 0\% Insulation and 2" Hole

$I L=24.5+10 \log .15$

$I L=16.3 \mathrm{~dB}$

Enclosure with $100 \%$ Insulation and 2" Hole

$I L=24.5+10 \log .45$

$I L=21.03 \mathrm{~dB}$

Enclosure with 0\% Insulation and 4" Hole

$I L=22.5+10 \log .15$

$I L=14.3 \mathrm{~dB}$

Enclosure with $100 \%$ Insulation and 4" Hole 
$I L=22.5+10 \log .45$

$I L=19.0 \mathrm{~dB}$

General equation for predicting Insertion Loss based on transmission loss and percent insulation added

$I L=T L-X, d B$

Enclosure with $0 \%$ insulation added

$I L=25.5-20$

$I L=5.5 \mathrm{~dB}$

Enclosure with 50\% insulation added

$I L=25.5-15$

$I L=10.5 \mathrm{~dB}$

Enclosure with $100 \%$ insulation added

$I L=25.5-10$

$I L=15.5 \mathrm{~dB}$ 